\title{
How the amygdala affects emotional memory by altering brain network properties
}

\author{
Erno J. Hermans ${ }^{1,2}$ \\ Francesco P. Battaglia ${ }^{1,2,3}$ \\ Piray Atsak ${ }^{1,2}$ \\ Lycia D. de Voogd ${ }^{1,2}$ \\ Guillén Fernández ${ }^{1,2}$ \\ Benno Roozendaal ${ }^{1,2}$
}

1. Donders Institute for Brain, Cognition and Behaviour, Radboud University Nijmegen, Nijmegen, 6500 HB, The Netherlands

2. Department for Cognitive Neuroscience, Radboud University Medical Centre, Nijmegen, 6525 EZ, The Netherlands

3. Departments for Neuroinformatics and Neurophysiology, Faculty of Science, Radboud University Nijmegen, Nijmegen, 6525 AJ, The Netherlands

Neurobiology of Learning and Memory 112, 2-16.

DOI: 10.1016/j.nlm.2014.02.005

Corresponding author:

Erno J. Hermans

Donders Institute for Brain, Cognition and Behaviour

Centre for Cognitive Neuroimaging

P.O. Box 9101

6500 HB Nijmegen

The Netherlands

$\mathrm{Ph}:+31(0) 243668294$

Fx: +31(0)243610989

e-mail: erno.hermans@donders.ru.nl

Key words: amygdala, emotional memory, stress hormones, memory consolidation, connectivity 


\begin{abstract}
The amygdala has long been known to play a key role in supporting memory for emotionally arousing experiences. For example, classical fear conditioning depends on neural plasticity within this anterior medial temporal lobe region. Beneficial effects of emotional arousal on memory, however, are not restricted to simple associative learning. Our recollection of emotional experiences often includes rich representations of, e.g., spatiotemporal context, visceral states, and stimulus-response associations. Critically, such memory features are known to bear heavily on regions elsewhere in the brain. These observations led to the modulation account of amygdala function, which postulates that amygdala activation enhances memory consolidation by facilitating neural plasticity and information storage processes in its target regions. Rodent work in past decades has identified the most important brain regions and neurochemical processes involved in these modulatory actions, and neuropsychological and neuroimaging work in humans has produced a large body of convergent data. Importantly, recent methodological developments make it increasingly realistic to monitor neural interactions underlying such modulatory effects as they unfold. For instance, functional connectivity network modeling in humans has demonstrated how information exchanges between the amygdala and specific target regions occur within the context of large-scale neural network interactions. Furthermore, electrophysiological and optogenetic techniques in rodents are beginning to make it possible to quantify and even manipulate such interactions with millisecond precision. In this paper we will discuss that these developments will likely lead to an updated view of the amygdala as a critical nexus within large-scale networks supporting different aspects of memory processing for emotionally arousing experiences.
\end{abstract}




\section{Introduction}

Stressful and emotionally arousing experiences are preferentially retained in memory (Joëls, Fernández, \& Roozendaal, 2011; Schacter, 1999). It has long been known that the amygdala, an anterior medial temporal lobe structure, plays a pivotal role in this usually highly adaptive phenomenon. The notion that the amygdala is involved in affective processing dates back to the classic report by Klüver and Bucy (1937) on the effects of temporal lobectomy in rhesus monkeys. Bilateral lesions of this region were shown to result in striking behavioral changes, including visual agnosia, dietary changes, and hypersexuality, but also profound alterations in affective behaviors, including tameness and loss of fear. Further investigations into these effects by Weiskrantz in the 1950s demonstrated that these affective changes were largely due to anteromedial temporal lobe lesions, particularly to the amygdala (Weiskrantz, 1956). Weiskrantz' work also demonstrated that amygdala lesions not only block the expression of conditioned fear, but also impair new fear learning. This observation set the stage for a line of research into the role of the amygdala in emotional memory that now spans multiple decades (McGaugh \& Roozendaal, 2002; Phelps \& LeDoux, 2005; Roozendaal, McEwen, \& Chattarji, 2009a). Initially, this research focused on the amygdala proper as a storage site for associations underlying fear memory (Davis \& Whalen, 2000; LeDoux, 2000). For instance, it was shown that fear learning depends on the induction of neural plasticity within the basolateral complex of the amygdala (BLA) (Miserendino, Sananes, Melia, \& Davis, 1990; Rogan, Stäubli, \& LeDoux, 1997). These findings led to the view that the BLA might be a crucial site where sensory input converges and synaptic plasticity can produce lasting changes in emotional responses to environmental stimuli.

However, the beneficial effects of emotional arousal on memory extend well beyond associative fear learning. Recollection of emotional experiences typically includes not only representations of sensory cues, but, for example, also of spatial and temporal context in which these have been encountered (Christianson, 1992; Diamond, Campbell, Park, Halonen, \& Zoladz, 2007; Phelps, 2004; Sandi \& Pinelo-Nava, 2007). Importantly, such types of declarative memory rely heavily on neural systems elsewhere in the brain (Bird \& Burgess, 2008; Henke, 2010). This notion has been corroborated by an extensive body of evidence documenting beneficial effects of stress hormones and neurotransmitters released during emotionally arousing experiences on various types of memory, both in rodents (McGaugh, 1989) and in humans (Lupien, Maheu, Tu, Fiocco, \& Schramek, 2007; Schwabe, Joëls, Roozendaal, Wolf, \& Oitzl, 2012). These developments led to the proposal that the amygdala contributes to enhancement of memory for emotional events primarily by integrating these neuromodulatory influences and modulating mnemonic activity and synaptic plasticity in other brain regions (McGaugh \& Roozendaal, 2002; Roozendaal, McEwen, \& Chattarji, 2009a). Research into the role of the amygdala in influencing memory consolidation processes in other memory systems was pioneered by James L. McGaugh and colleagues. However, this modulation hypothesis of amygdala function can historically be traced back to Ralph W. Gerard, who hypothesized already many years before the first experiments were performed that amygdalar nuclei could "modify the ease and completeness of experience fixation even if the nuclei were not themselves the loci of engrams" (Gerard, 1961). 
As we will address below, the modulation hypothesis has received wide empirical support over the years. Rodent studies have utilized pharmacological manipulations, selective lesions and immediate-early gene activation to delineate the relevant structures, pathways and neurochemical processes. This work has dovetailed tightly with behavioral, psychopharmacological, neuropsychological, and neuroimaging studies in humans. However, more recent methodological developments make it increasingly feasible to monitor neural activity in real-time, and thus to explore how information is processed and exchanged between brain regions. For instance, the rapid proliferation of techniques for functional connectivity network modeling in humans using functional magnetic resonance imaging (fMRI) has made it possible to study interactions within largescale neural systems in the human brain (Raichle, 2009). Findings gathered using these techniques have generated novel insights into how brain regions implicated in different types of memory are part of distinct large-scale connectivity networks (Ranganath \& Ritchey, 2012). As explained below, these findings yield important heuristics for translation back to basic neuroscience, which offers the technology to investigate these processes more mechanistically and in more spatial and temporal detail. For instance, in vivo electrophysiological techniques in rodents now make it possible to simultaneously record activity of neuronal ensembles distributed across different brain regions during different phases of memory processing (Buzsáki, 2004), while optogenetic techniques allow manipulations of specific neural connections with millisecond precision (Boyden, Zhang, Bamberg, Nagel, \& Deisseroth, 2005; Tye et al., 2011). Future application of these techniques to the amygdala and its many efferent connections will lead to a sophisticated understanding of how the amygdala engages stress hormone and neurotransmitter systems to modulate largescale network properties and influence distant neural processes underlying the formation and consolidation of memory for emotionally arousing experiences.

\section{Role of the amygdala in memory modulation}

During an emotionally arousing episode, stress hormones (epinephrine and glucocorticoids) are secreted from the adrenal glands and several neurotransmitters and neuropeptides are released in the brain (Joëls \& Baram, 2009). The amygdala plays a critical role in integrating these various neuromodulatory influences on memory (McGaugh, 1989; 2004). The modulation hypothesis proposes that during and shortly after an emotionally arousing experience, the amygdala engages stress-related hormones and neurotransmitters to enhance the consolidation and storage of memory within other parts of the brain. Studies performed since the 1970s have produced a wealth of convergent data supporting this notion. Gold and van Buskirk (1975) were the first to report that systemic post-learning injection of the adrenomedullary hormone epinephrine enhances long-term retention of inhibitory avoidance training. The epinephrine effect was both dosedependent and time-dependent. Memory enhancement was greatest when epinephrine was administered shortly after training (Gold \& Van Buskirk, 1975). Epinephrine-induced memory enhancement has now been extended to many other types of training in rodents (Costa-Miserachs, Portell-Cortés, Aldavert-Vera, TorrasGarcía, \& Morgado-Bernal, 1994; Introini-Collison \& McGaugh, 1986; Sternberg, Isaacs, Gold, \& McGaugh, 1985) as well as declarative memory in humans (Cahill \& Alkire, 2003). Similar findings were obtained, for example, with post-learning elevations of adrenocortical glucocorticoid hormones in both 
rodents (Cottrell \& Nakajima, 1977; Hui et al., 2004; Okuda, Roozendaal, \& McGaugh, 2004; Roozendaal \& McGaugh, 1996; Zorawski \& Killcross, 2002) and humans (van Marle, Hermans, Qin, Overeem, \& Fernández, 2013; Wilhelm, Wagner, \& Born, 2011). However, these stress hormones appear to affect memory consolidation only for emotionally arousing experiences in the presence of arousal-induced noradrenergic activity (Borrell, de Kloet, \& Bohus, 1984; Borrell, de Kloet, Versteeg, \& Bohus, 1983; Liang, Juler, \& McGaugh, 1986; Okuda et al., 2004; Roozendaal, Carmi, \& McGaugh, 1996; Roozendaal, Okuda, van der Zee, \& McGaugh, 2006b). A similar dependency on concurrent noradrenergic activity was found for other memory-enhancing compounds such as the opiate receptor antagonist naloxone (Izquierdo \& Graudenz, 1980), corticotropin-releasing factor (CRF) (Lee, Lee, Wang, \& Lin, 1993), and cannabinoid compounds (Atsak, Roozendaal, \& Campolongo, 2012). As we will discuss below, extensive evidence indicates that the effects of various stress-related neurochemical changes converge onto arousal-induced activation of noradrenergic transmission within the amygdala, which in turn interacts with other brain regions in regulating the consolidation of different types of memory. Although in this paper we will mainly focus on the role of the amygdala in regulating the encoding and consolidation of memory, there exists now compelling evidence that amygdala activity, via its interactions with other brain regions, is also crucially involved in regulating stress hormone and emotional arousal effects on other aspects of memory processing such as memory retrieval, memory extinction, and working memory (Roozendaal, Hahn, Nathan, de Quervain, \& McGaugh, 2004a; Roozendaal, McReynolds, \& McGaugh, 2004b).

\section{Evidence for a modulatory role of the amygdala in rodents}

Findings of experiments by Kesner (Kesner et al., 1983; Ellis et al., 1981) and Gallagher (Gallagher et al., 1981) were the first to suggest that the noradrenergic system of the amygdala is involved in influencing memory consolidation. A $\beta$-adrenoceptor antagonist administered into the amygdala post-training was shown to impair memory, while concurrent infusion of norepinephrine blocked this memory impairment (Gallagher et al., 1981). Many subsequent studies found that post-training infusions of norepinephrine or $ß$-adrenoceptor agonists into the amygdala (or selectively into the BLA) enhance memory consolidation for a wide variety of training experiences (Bianchin, Mello e Souza, Medina, \& Izquierdo, 1999; Ferry \& McGaugh, 1999; Hatfield \& McGaugh, 1999; Huff, Wright-Hardesty, Higgins, Matus-Amat, \& Rudy, 2005; Introini-Collison, Dalmaz, \& McGaugh, 1996; Introini-Collison, Miyazaki, \& McGaugh, 1991; Introini-Collison, Saghafi, Novack, \& McGaugh, 1992; Lalumiere, Buen, \& McGaugh, 2003; Lalumiere, Nawar, \& McGaugh, 2005; Liang et al., 1986; Liang, Chen, \& Huang, 1995; Liang, McGaugh, \& Yao, 1990; Roozendaal, Castello, Vedana, Barsegyan, \& McGaugh, 2008). Experiments investigating the role of amygdala norepinephrine in modulating memory consolidation have generally used emotionally arousing training conditions that induce the release of high levels of norepinephrine in the amygdala. However, as is shown in Figure 1, recent findings indicate that post-training noradrenergic activation of the BLA also enhances memory of a lowarousing object recognition training experience that otherwise would not induce strong memory (Roozendaal et al., 2008). Thus, these findings suggest that in the absence of high arousal, noradrenergic activation of the BLA is sufficient to enhance memory consolidation. Noradrenergic activity within the BLA also plays an 
important role in mediating the modulatory effects of many other hormones and neurotransmitters on memory consolidation (Roozendaal, 2007). For example, a B-adrenoceptor antagonist infused into the BLA post-learning blocks the memory-modulatory effects of epinephrine, glucocorticoids, cannabinoids, CRF as well as GABAergic and opioid peptidergic drugs (Atsak et al., 2012; Introini-Collison, Nagahara, \& McGaugh, 1989; Quirarte, Roozendaal, \& McGaugh, 1997; Roozendaal et al., 2008; Roozendaal \& McGaugh, 2011).

The extensive evidence that noradrenergic activity within the amygdala modulates memory consolidation suggests that emotionally arousing learning experiences should induce the release of norepinephrine within the amygdala. Findings of studies using in vivo microdialysis and high-performance liquid chromatography (HPLC) to measure ongoing changes in norepinephrine levels in the amygdala strongly support this implication. Footshock stimulation comparable to that used for inhibitory avoidance training, the task used in many rodent studies, significantly increases amygdala norepinephrine release (Galvez, Mesches, \& McGaugh, 1996; Quirarte, Galvez, Roozendaal, \& McGaugh, 1998). Moreover, drugs and hormones that enhance memory consolidation augment footshock-induced increases in norepinephrine levels in the amygdala and drugs that impair consolidation decrease amygdala norepinephrine levels (Hatfield, Spanis, \& McGaugh, 1999; Kawahara, Hesselink, van Scharrenburg, \& Westerink, 2004; McReynolds et al., 2010; Quirarte et al., 1998; Williams, Men, Clayton, \& Gold, 1998). McIntyre et al. (2002) found that norepinephrine levels in the amygdala increased significantly after inhibitory avoidance training. Additionally, and importantly, the retention performance of individual animals tested the following day correlated highly with levels of amygdala norepinephrine induced by the training. Thus, there is now extensive evidence indicating that emotionally arousing experiences induce the release of norepinephrine into the BLA and that this noradrenergic activity plays an important role in mediating the modulatory influences of other hormones and neurotransmitters on memory consolidation of these experiences (Roozendaal \& McGaugh, 2011).

As discussed above, many of the experiments investigating BLA involvement in memory consolidation have used inhibitory avoidance training (Aggleton, 2000; Izquierdo et al., 1997; McGaugh \& Izquierdo, 2000; Parent \& McGaugh, 1994; Wilensky, Schafe, \& LeDoux, 2000). However, comparable effects of post-training amygdala treatments have been obtained with many different kinds of training, including both high-arousing and low-arousing tasks, such as contextual fear conditioning (Lalumiere et al., 2003; Sacchetti, Lorenzini, Baldi, Tassoni, \& Bucherelli, 1999; Vazdarjanova \& McGaugh, 1999), cued fear conditioning (Hui et al., 2004; Roozendaal, Hui, Hui, Berlau, McGaugh, et al., 2006a; Sacchetti et al., 1999; Schafe \& LeDoux, 2000), Y-maze discrimination training (McGaugh, Introini-Collison, \& Nagahara, 1988), change in reward magnitude (Salinas, Introini-Collison, Dalmaz, \& McGaugh, 1997), conditioned place preference (Hsu, Schroeder, \& Packard, 2002; Schroeder \& Packard, 2003; 2004), radial-arm maze appetitive training (Packard \& Chen, 1999), water-maze spatial and cued training (Packard \& Teather, 1998; Packard, Cahill, \& McGaugh, 1994), conditioned taste aversion (Miranda, LaLumiere, Buen, BermudezRattoni, \& McGaugh, 2003; Miranda, Quirarte, Rodriguez-Garcia, McGaugh, \& Roozendaal, 2008), olfactory training (Kilpatrick \& Cahill, 2003a), object recognition (Roozendaal, Okuda, van der Zee, \& 
McGaugh, 2006b), extinction of contextual fear conditioning (Berlau \& McGaugh, 2006), and extinction of conditioned reward (Schroeder \& Packard, 2003). As these different training experiences are known to engage different brain systems (Gold, 2004; Izquierdo \& Medina, 1997; McGaugh, 2002; Packard \& Cahill, 2001; Packard \& Knowlton, 2002; Quillfeldt et al., 1996; Zanatta et al., 1996), the BLA-induced modulation no doubt involves influences on information processing occurring in these different brain regions. Packard and colleagues (Packard et al., 1994; Packard \& Teather, 1998) were the first to show that the amygdala can modulate memory processes in both the striatum (caudate nucleus) and hippocampus. Considerable evidence indicates that the striatum and hippocampus are involved in different aspects of memory (e.g., McDonald \& White, 1993; Packard \& Cahill, 2001; Packard \& McGaugh, 1992; 1996). These authors found that the stimulant drug amphetamine infused into the striatum after training on a water-maze task selectively enhanced memory of visually cued water-maze training, whereas amphetamine administered into the dorsal hippocampus selectively enhanced memory of spatial water-maze training. In contrast, amphetamine infused into the amygdala post-training enhanced memory of both cued and spatial training. Moreover, as inactivation of the amygdala prior to retention testing did not block the amphetamine effect on memory of either kind of training, these findings indicate that amygdala activation modulates the consolidation of both striatal-dependent and hippocampus-dependent memory but is not a critical locus of memory for either type of training.

Studies of the effects of post-training administration of glucocorticoid hormones provide additional evidence of BLA-hippocampus interactions in memory consolidation. As is shown in Figure 2, unilateral post-training intra-hippocampal infusions of the specific glucocorticoid receptor (GR) agonist RU 28362 enhance rats' retention of inhibitory avoidance training and the enhancement is blocked by ipsilateral infusions of a $\beta$-adrenoceptor antagonist into the BLA. These findings clearly indicate that arousal-associated noradrenergic activity within the BLA is a co-requirement in enabling glucocorticoid effects on memory processing in the hippocampus. Noradrenergic stimulation of the BLA that enhances memory consolidation also increases dorsal hippocampal levels of activity-regulated cytoskeletal protein (Arc) (McIntyre et al., 2005), an immediate-early gene implicated in hippocampal synaptic plasticity and memory consolidation processes (Guzowski et al., 2000). Additionally, inactivation of the BLA with post-training infusions of lidocaine impairs memory consolidation and decreases Arc protein levels in the dorsal hippocampus (McIntyre et al., 2005). The finding that intra-BLA infusions of muscimol attenuate the increase in Arc mRNA induced by contextual fear conditioning provides further evidence that the BLA modulates memory consolidation via regulation of Arc expression in the hippocampus (Huff et al., 2006).

Studies of BLA influences on hippocampal neural plasticity provide additional important evidence of amygdala-hippocampal interactions (Abe, 2001). Electrical stimulation of the BLA enhances the induction of long-term potentiation (LTP) in the dentate gyrus of the hippocampus (Akirav \& Richter-Levin, 1999; Almaguer-Melian, Martínez-Martí, Frey, \& Bergado, 2003; Frey, Bergado-Rosado, Seidenbecher, Pape, \& Frey, 2001; Ikegaya, Saito, \& Abe, 1995; Vouimba \& Richter-Levin, 2013), but appear to block LTP in the CA1 region of the hippocampus (Vouimba \& Richter-Levin, 2005; 2013). Also, selective lesions of the BLA or infusions of a $\beta$-adrenoceptor antagonist into the BLA block the induction of LTP in the dentate gyrus 
(Ikegaya et al., 1995; Ikegaya, Nakanishi, Saito, \& Abe, 1997; Ikegaya, Saito, \& Abe, 1994). Norepinephrine and glucocorticoids both influence the effects of BLA stimulation on dentate gyrus LTP (Akirav \& RichterLevin, 2002; Vouimba, Yaniv, \& Richter-Levin, 2007). Recent findings indicate that electrical stimulation of the BLA also enhances LTP at cortical synapses onto striatal neurons (Popescu, Saghyan, \& Paré, 2007) and that coherent gamma oscillations couple the BLA and striatum during learning (Popescu, Popa, \& Paré, 2009). Such findings fit well with the evidence that amygdala activation enhances the consolidation of both hippocampus and striatal-dependent memory (Packard et al., 1994; Packard \& Teather, 1998).

Findings of several studies indicate that the BLA also modulates neocortical functioning involved in memory consolidation. Neurons within the BLA project directly to the entorhinal cortex (Paré \& Gaudreau, 1996; Paré, Dong, \& Gaudreau, 1995; Petrovich, Canteras, \& Swanson, 2001; Pikkarainen, Rönkkö, Savander, Insausti, \& Pitkänen, 1999). Memory enhancement induced by post-training drug infusions administered into the entorhinal cortex (Izquierdo \& Medina, 1997) requires a functioning BLA, as lesions of the BLA prevent the memory enhancement induced by 8 -bromo-cAMP infused post-training into the entorhinal cortex (Roesler, Roozendaal, \& McGaugh, 2002). BLA lesions or blocking of $\beta$-adrenoceptors in the BLA also prevent the memory-enhancing effects of 8-bromo-cAMP infused post-training into the insular cortex (Miranda \& McGaugh, 2004) and of oxotremorine infused into the rostral anterior cingulate cortex (Malin, Ibrahim, Tu, \& McGaugh, 2007). There is also evidence indicating that the BLA and the medial prefrontal cortex, a brain region involved in higher cognitive processing, interact in regulating memory consolidation. Inactivation of the medial prefrontal cortex with an AMPA receptor antagonist impairs consolidation of inhibitory avoidance memory (Liang, Hu, \& Chang, 1996). In contrast, activation of noradrenergic and dopaminergic mechanisms in the medial prefrontal cortex enhances the consolidation of inhibitory avoidance training and trace fear conditioning (Liang, 2001; Runyan \& Dash, 2004). The GR agonist RU 28362 infused into the medial prefrontal cortex induces similar memory enhancement (Barsegyan, Mackenzie, Kurose, McGaugh, \& Roozendaal, 2010; Roozendaal, McReynolds, van der Zee, Lee, et al., 2009b). However, lesions of the BLA block the GR agonist-induced memory enhancement. Furthermore, consistent with the evidence of functional connectivity between both brain regions (McDonald, 1991; Pérez-Jaranay \& Vives, 1991; Rosenkranz \& Grace, 2002), the administration of RU 28362 into the medial prefrontal cortex after inhibitory avoidance training increases BLA activity, as assessed with phosphorylation of extracellular signal-regulated kinase type 1 and 2 (Erk1/2), a member of the mitogenactivated protein kinase family (Roozendaal, McReynolds, van der Zee, Lee, et al., 2009b). Blockade of this increase in phosphorylated Erk1/2 levels in the BLA with a MEK inhibitor prevents the memory enhancement induced by medial prefrontal cortex GR agonist infusions. Interestingly, infusions of a GR agonist into the BLA induce a similar increase in phosphorylated Erk1/2 activity in the medial prefrontal cortex, suggesting bi-directional interactions between both brain regions in regulating memory consolidation.

In conclusion, there is now a wealth of evidence from experiments using primarily local drug administration supporting the hypothesis that neuromodulatory influences on the amygdala after learning promote memory processing in regions elsewhere in the brain. These regions include the hippocampus, entorhinal cortex, striatum, medial prefrontal cortex, anterior cingulate cortex, and insula, and this list is 
likely to expand in the future. We will now turn to human neuropsychological and neuroimaging work on the involvement of the amygdala in modulating distinct types of memory.

\section{Evidence for a modulatory role of the amygdala in humans}

The first studies investigating the role of the amygdala in memory modulation in humans were performed in patients with damage to this brain region. In agreement with rodent findings, epilepsy patients who underwent unilateral anteromedial temporal lobe resection exhibited impaired acquisition of conditioned fear (LaBar, LeDoux, Spencer, \& Phelps, 1995; Peper, Karcher, Wohlfarth, Reinshagen, \& LeDoux, 2001). A similar deficit was observed in a patient with Urbach-Wiethe disease (also known as lipoid proteinosis) (Bechara et al., 1995), a rare congenital disorder that causes a progressive and selective calcification of the amygdala, particularly in the BLA region (Terburg et al., 2012). Critically, in line with the modulation hypothesis, effects of amygdala lesions were not confined to fear learning. Urbach-Wiethe patients exhibited broader memory deficits that extend into the domain of declarative memory (Markowitsch et al., 1994; Thornton et al., 2008). Urbach-Wiethe patients, for example, fail to show enhancement of episodic memory for emotional events within a story (Adolphs, Cahill, Schul, \& Babinsky, 1997; Cahill, Babinsky, Markowitsch, \& McGaugh, 1995), a finding that closely resembles the effects of $\beta$-adrenoceptor blockade in healthy volunteers (Cahill, Prins, Weber, \& McGaugh, 1994). A larger group of Urbach-Wiethe patients exhibited impaired recognition memory for emotionally arousing photographs (Siebert, Markowitsch, \& Bartel, 2003). Amygdala damage also results in a loss of the benefit of gist over detail memory for emotional episodes (Adolphs, Denburg, \& Tranel, 2001; Adolphs, Tranel, \& Buchanan, 2005), suggesting that the amygdala modulates sensory processes (Henckens, Hermans, Pu, Joëls, \& Fernández, 2009; Vuilleumier, Richardson, Armony, Driver, \& Dolan, 2004) as well as prefrontal regions involved in extracting and representing gist (Qin, Hermans, van Marle, \& Fernández, 2012; Qin, van Marle, Hermans, \& Fernández, 2011) already at the time of encoding. Unilateral anteromedial temporal lobe resection patients furthermore show impaired consolidation of emotional information. Unlike control participants, patients did not exhibit an increase in memory for emotionally arousing words over a 1-hour period of consolidation (LaBar \& Phelps, 1998).

A critical development in human research on the amygdala was the arrival of non-invasive techniques for functional neuroimaging. Initial studies used positron emission tomography (PET) to demonstrate amygdala activity in response to socially salient stimuli such as facial expressions (Breiter et al., 1996; Morris et al., 1996), but also during fear conditioning (Fredrikson, Wik, Fischer, \& Andersson, 1995; Hugdahl et al., 1995; Morris, Friston, \& Dolan, 1998). The temporal resolution of PET, however, is insufficient to detect transient responses evoked by discrete events such as conditioned stimuli. This possibility came with blood oxygenation level-dependent fMRI (BOLD-fMRI). A wave of BOLD-fMRI studies confirmed the hypothesis that the amygdala responds to conditioned stimuli (Buchel, Dolan, Armony, \& Friston, 1999; Büchel, Morris, Dolan, \& Friston, 1998; Cheng, Knight, Smith, Stein, \& Helmstetter, 2003; LaBar, Gatenby, Gore, LeDoux, \& Phelps, 1998; Schiller et al., 2008). A number of studies also reported hippocampal coactivation during trace conditioning (Buchel et al., 1999; Cheng, Disterhoft, Power, Ellis, \& 
Desmond, 2008) and contextual conditioning (Kalisch et al., 2006; Marschner, Kalisch, Vervliet, Vansteenwegen, \& Büchel, 2008).

Functional MRI has furthermore been used to demonstrate that noradrenergic activity increases excitability of the human amygdala already at the time of encoding. Induction of acute stress unselectively increased amygdala responses to presentations of emotional facial expressions, stimuli that robustly elicit amygdala activation (van Marle, Hermans, Qin, \& Fernández, 2009). Although exposure to acute stress likely causes a surge of norepinephrine from the locus coeruleus (Valentino \& van Bockstaele, 2008), this finding may be explained by neuromodulatory mechanisms other than norepinephrine. Subsequent studies, however, showed that amygdala responses to emotional stimuli are enhanced in carriers of a deletion variant of $A D R A 2 B$ (the gene encoding the $\alpha_{2 b}$-adrenoceptor), who have increased noradrenergic tone (Rasch et al., 2009). Stress induction was also shown to cause a stronger increase in amygdala responses in $A D R A 2 B$ deletion carriers (Cousijn et al., 2010). Furthermore, pharmacological studies showed that $\beta$-adrenoceptor blockade with propranolol reduces the amygdala response to emotional material (Hurlemann et al., 2010; Strange \& Dolan, 2004; van Stegeren et al., 2005), whereas the selective norepinephrine-reuptake inhibitor reboxetine has an opposite effect (Onur et al., 2009). Thus, ample evidence supports the involvement of norepinephrine in modulating amygdala activity in humans.

In line with rodent findings of adrenergic-glucocorticoid interactions (McGaugh \& Roozendaal, 2002), one study showed that the effects of propranolol on amygdala responses to emotional stimuli interact with endogenous cortisol (van Stegeren et al., 2007). A pharmacological experiment involving both reboxetine and hydrocortisone administration observed the largest amygdala responses when both drugs were administered simultaneously (Kukolja et al., 2008), although studies combining yohimbine, a noradrenergic stimulant, and hydrocortisone administration have produced less clear results (Schwabe, Hoffken, Tegenthoff, \& Wolf, 2013a; van Stegeren, Roozendaal, Kindt, Wolf, \& Joëls, 2010). A study in which only hydrocortisone was administered, without manipulation of noradrenergic activity, found a decreased amygdala responsiveness at both 75 and 285 min after administration, suggesting that such slow effects of glucocorticoids might be involved in the recovery from stress (Henckens, van Wingen, Joëls, \& Fernández, 2010). Consistent with the findings from animal studies, glucocorticoids therefore appear to potentiate amygdala responses in humans primarily during the time window of elevated noradrenergic activity.

In further agreement with the modulation view, a number of studies have found that amygdala activation during learning influences mnemonic processes that depend on other brain regions. Early studies using PET found that amygdala activity during encoding is associated with interindividual differences in hippocampal-dependent declarative memory for emotionally arousing experiences (Cahill et al., 1996; 2001; Hamann, Ely, Grafton, \& Kilts, 1999). With BOLD-fMRI, such findings were extended to trial-by-trial variation in success of memory formation (Cahill, Uncapher, Kilpatrick, Alkire, \& Turner, 2004; Canli, Zhao, Brewer, Gabrieli, \& Cahill, 2000; Kensinger \& Corkin, 2004). One such study showed that encodingrelated activation of the amygdala and hippocampus was more strongly correlated for emotionally arousing 
than for neutral stimuli (Dolcos, Labar, \& Cabeza, 2004). Structural equation modeling of PET data indicates that the amygdala modulates activity of the parahippocampal gyrus and ventrolateral prefrontal cortex during encoding of emotional memory (Kilpatrick \& Cahill, 2003b). B-adrenoceptor blockade with propranolol during memory encoding was shown to diminish the enhancement of hippocampal activity for emotional items at retention testing 10 hours later, when propranolol was no longer active (Strange \& Dolan, 2004). Amygdala modulation of hippocampal-dependent encoding processes was demonstrated more directly in an fMRI study involving patients with variable lesions in the hippocampus and amygdala (Richardson, Strange, \& Dolan, 2004). While hippocampal lesions blocked declarative memory for both emotional and neutral stimuli, amygdala lesions selectively impaired memory for emotional items. Hippocampal activity associated with successful memory formation for emotional items was negatively associated with the extent of amygdala lesions. Thus, emotional enhancement of encoding efficiency within the hippocampus depends on the integrity of the amygdala.

Emotional modulation of memory is not restricted to amygdala influences on the hippocampus. As described above, the hippocampus and striatum comprise functionally distinct memory systems (McDonald \& White, 1993; Packard et al., 1994). While the hippocampal memory system in humans is commonly thought to support spatial and episodic aspects of memory (Henke, 2010), the striatum is a critical region for stimulus-response learning and habit formation (Ashby, Turner, \& Horvitz, 2010; Schwabe \& Wolf, 2013). Recent findings in humans have shown that this latter system is particularly augmented during acute stress. In navigation learning, for instance, stress induction caused a shift from spatial towards stimulus-response learning strategies (Schwabe et al., 2007). In line with the notion that stress causes relapse in addiction (Arnsten, 2009), stress induction causes a persistence of habitual behavior despite devaluation of its outcomes (Schwabe \& Wolf, 2009). Neuroimaging work has confirmed that neural activity during a probabilistic category learning task shifts from hippocampus to striatum under stress (Schwabe \& Wolf, 2012). A recent study has shown that this effect is accompanied by a shift in connectivity of the amygdala from hippocampus to striatum, thus providing direct human evidence supporting the view that the amygdala plays a critical role in inducing this shift between memory systems during emotionally arousing situations (Schwabe, Tegenthoff, Hoffken, \& Wolf, 2013b).

In conclusion, findings of neuropsychological and neuroimaging studies in humans are in general agreement with those of animal experiments, and confirm the critical role of arousal-associated noradrenergic activation of the amygdala in modulating memory processes that take place elsewhere in the brain. One notable difference between animal and human work is that human studies have focused more strongly on memory encoding than on consolidation, while the opposite is true for animal work. By showing that the amygdala also modulates encoding-related activity, human data have provided an important extension of rodent work. In the following section, we will turn to studies into the architecture of connectivity networks involving the amygdala and other brain regions involved in memory processing of emotionally arousing experiences. 


\section{Human neuroimaging work on network interactions involving the amygdala}

Guided by animal research, human neuroimaging studies initially employed targeted region-of-interest analyses to focus exclusively on the role of the amygdala. However, numerous limitations aside, BOLDfMRI in humans has one critical advantage over animal work using selective lesions and targeted pharmacological interventions. This advantage is that magnetic resonance imaging protocols used for fMRI easily reach full-brain coverage without compromising temporal resolution beyond the minimum requirements to sample event-related hemodynamic responses, and thus allow for simultaneous investigation of activity across the entire brain. Consequently, even though fMRI studies into the amygdala often focus on findings from this area only, the same analyses are performed throughout the brain. Findings observed in unexpected regions, however, are usually only reported in tables and often remain uninterpreted due to lack of space, interest, or prior knowledge about those regions.

Ironically, in the broader field of human functional neuroimaging, it were the findings that ended up in such tables that led to some of the field's most influential discoveries. It turned out that particular sets of distributed brain regions systematically co- or deactivate in response to widely different cognitive tasks (Corbetta \& Shulman, 2002; Raichle et al., 2001). Meta-analyses across large numbers of functional imaging studies furthermore revealed that regions that exhibit similar evoked activity also show correlated intrinsic BOLD signal fluctuations $(<.1 \mathrm{~Hz})$ during rest (Greicius, Krasnow, Reiss, \& Menon, 2003; Raichle et al., 2001; Smith et al., 2009), suggesting that such regions form large-scale neural networks. The topography of such networks moreover corresponds with structural connectivity data (van den Heuvel, Mandl, Kahn, \& Hulshoff Pol, 2009). Recent years has seen a rapid progress in mapping the anatomy of a variety of such networks (Damoiseaux et al., 2006; Raichle, 2009; Raichle \& Snyder, 2007).

The first large-scale neural system that was identified using these techniques was a set of brain regions that consistently deactivates in response to tasks requiring goal-directed attention and is referred to as the default mode network (Raichle et al., 2001). This network most prominently includes the (ventro)medial prefrontal cortex, inferior parietal lobule, and posterior cingulate and retrosplenial cortex (Buckner, Andrews-Hanna, \& Schacter, 2008). Notably, these brain regions also exhibit substantial resting functional connectivity with medial temporal lobe structures, including the hippocampus and amygdala (Buckner et al., 2008). Robust default mode network activation during waking rest has led to the suggestion that this network supports "offline" associative processing (Bar, 2007) and prospection (Buckner \& Carroll, 2007). Such a notion concurs with rodent findings of coupling between the hippocampus and prefrontal cortex (Ji \& Wilson, 2007; Qin, McNaughton, Skaggs, \& Barnes, 1997; Wierzynski, Lubenov, Gu, \& Siapas, 2009), in particular the (ventro)medial prefrontal cortex (Takehara-Nishiuchi \& McNaughton, 2008), during waking rest. Resting hippocampal-neocortical connectivity, or default mode network activity, has therefore been proposed to support systems consolidation, in particular the integration of newly encoded information into pre-existing associative networks (e.g., Ranganath \& Ritchey, 2012) or schemas (Preston \& Eichenbaum, 2013; van Kesteren, Fernández, Norris, \& Hermans, 2010; van Kesteren, Ruiter, Fernández, \& Henson, 2012). The limited temporal resolution of BOLD-fMRI, however, makes it difficult to investigate the precise timing and directionality of these interactions. 
Studies into amygdala function likewise led to a number of serendipitous observations. Emotionally arousing tasks that activate the amygdala were shown to lead to a consistent and robust coactivation of a specific set of other brain regions. This set includes the dorsal anterior cingulate cortex and medial prefrontal cortex, and the anterior portion of the insula (often extending into the inferior frontal gyrus). These regions are associated with autonomic control and visceral perception (Critchley, 2005). Furthermore, coactivated brain regions include areas involved in attentional regulation (thalamus and inferotemporal and temporoparietal regions) (Corbetta, Patel, \& Shulman, 2008), stimulus-response learning and habitual behavior (striatum), catecholaminergic signaling (brainstem and midbrain nuclei), and regulation of peripheral stress effector systems (hypothalamus) (Ulrich-Lai \& Herman, 2009). Meta-analyses of human functional neuroimaging studies have indicated that these brain regions respond consistently to a variety of salient stimuli, including unconditioned stimuli, conditioned stimuli, pain, and empathy for pain (Kober et al., 2008). An important observation was that these brain regions also exhibit coordinated activity in the resting brain, and thus form a distinct intrinsic connectivity network (Menon, 2011; Menon \& Uddin, 2010; Seeley et al., 2007). Although the exact topology of the salience network remains subject to debate, there is wide agreement regarding its core components, namely the dorsal anterior cingulate cortex and anterior insula (Dosenbach, Fair, Cohen, Schlaggar, \& Petersen, 2008; Hermans et al., 2011; Menon, 2011).

An influential hypothesis is that this network integrates various neurocognitive functions relevant to processing salient stimuli (Seeley et al., 2007), including attentional vigilance, interoceptive representation, and homeostatic regulation. Attentional functions of the salience network are understood as a system for exogenous attention or reorienting (Corbetta et al., 2008). For instance, spontaneous activity in the salience network is associated with electroencephalographic signatures of alertness (Sadaghiani et al., 2010). Activation of the salience network is thought to facilitate switches of task sets within a more dorsal executive control system that regulates endogenous attention (Corbetta et al., 2008). Notably, theories of noradrenergic function propose a similar circuit-breaking or network switching function for noradrenergic projections towards the neocortex (Aston-Jones \& Cohen, 2005; Sara \& Bouret, 2012). Because noradrenergic neurons in the locus coeruleus exhibit tonically increased firing rates under stress (Aston-Jones \& Cohen, 2005; Valentino \& van Bockstaele, 2008), it was proposed that stress or emotional arousal causes a prolonged increase in neural excitability within brain regions comprising the salience network (Corbetta et al., 2008; Sara \& Bouret, 2012).

A recent study directly tested this hypothesis by quantifying functional connectivity within the salience network during exposure to a fear-related stressor, i.e., a movie fragment depicting extreme violence (Hermans et al., 2011). The strength of functional connectivity within the salience network increased in response to this stressor and was found to correlate positively with salivary levels of $\alpha$-amylase, a peripheral measure of adrenergic activity (Nater \& Rohleder, 2009). Network connectivity also correlated with levels of salivary cortisol and subjective ratings of negative affect induced by the movie clips. As shown in Figure 3, a follow-up experiment demonstrated that $ß$-adrenoceptor blockade with propranolol, but not the cortisolsynthesis inhibitor metyrapone, blocked the stress-induced increase in functional connectivity within this 
salience network (Hermans et al., 2011). Furthermore, resting connectivity within the salience network remained elevated during awake rest immediately following exposure to this stressor (van Marle, Hermans, Qin, \& Fernández, 2010). A critical suggestion of these theoretical accounts is that salience network activity is involved in the formation of an interoceptive representation of the physiological state evoked by prior salient events, and thus contributes to long-term memory and adaptation (Craig, 2008; Damasio \& Carvalho, 2013). The brain regions comprising the salience network indeed map remarkable well onto the regions modulated by the amygdala through noradrenergic mechanisms listed in the previous sections (e.g., dorsal anterior cingulate cortex, insula, and striatum). However, while attentional and homeostatic functions of the salience network have been explored quite extensively, mnemonic functions, and the role the amygdala in these, have up to now received little attention.

In sum, brain regions shown in rodent work to be modulated by the amygdala appear to exhibit wellorchestrated interactions as part of distinct large-scale networks. Prominently among these are the hippocampal complex and medial prefrontal cortex, which are part of the midline-centered default mode network, and insular, anterior cingulate, and striatal structures that are part of the salience network. A network understanding of these interactions and how they contribute to memory encoding and consolidation is just beginning to develop. In the following section, we will outline how these observations generate novel questions for future research, some of which can be addressed through back-translation to basic neuroscience.

\section{Rodent and primate electrophysiology work on network interactions and its extension to the amygdala}

Lesions, pharmacological interventions, and immediate early gene activation techniques in rodents have led to an identification of brain regions, pathways, and neurochemical processes involved in the consolidation of memory of emotionally arousing experiences. Human work has corroborated these findings, and has moreover offered an initial window onto the organization of neural interactions within large-scale neural ensembles, suggesting that the consolidation of emotional memories is a network process in which the amygdala plays a central role. However, to gain a true understanding of how information is processed, stored, and passed between brain regions, it is necessary to capture and manipulate transient and oscillatory phenomena that typically take place within a time window of milliseconds. This requires a temporal resolution that far exceeds what is possible with BOLD-fMRI. Sufficient temporal resolution can be achieved with novel technology for rodent studies such as high-density neural ensemble recordings (Buzsáki, 2004), which can be used to simultaneously record activity from ensembles distributed across different brain regions, and across longer periods of time. The study of memory processes in brain networks with such finegrained techniques has been pursued with great intensity in the past 20 years. However, as we will explain below, the role of the amygdala and stress-related neuromodulators in modulating these processes remains unclear. Nonetheless, this work fosters many new directions for exploration, and a picture complementary to that offered by behavioral, pharmacological, and imaging methods is beginning to emerge. 


\section{Electrophysiological recordings in the amygdala}

Only recently, researchers have started using electrophysiological techniques to directly record activity from neuronal ensembles within the amygdala. A substantial hurdle in this development has been the difficulty to selectively target subnuclei of the amygdala, which play different roles in the neural circuitry and have distinct functional correlates. Knowledge of the dynamics of amygdala networks and interactions with structures that support memory therefore remains relatively scarce.

In line with lesion work in rodents (Davis \& Whalen, 2000), electrophysiological studies revealed profound functional differentiations between centromedial and basolateral nuclei of the monkey amygdala (Mosher, Zimmerman, \& Gothard, 2010). In a task involving attentional orienting and viewing a variety of emotional images, centromedial neurons correlated more with the different phases of the task, whereas basolateral activity was more informative about the content of the stimuli. There was, however, considerable overlap between these response types across basolateral and centromedial nuclei, suggesting distributed information processing. Processing of complex visual stimuli in the BLA was analyzed in detail by Gothard et al. (2007). In agreement with BOLD-fMRI work in humans described above (Adolphs, 2003; Whalen, 2007), these authors found robust neural responses in the amygdala to socially salient stimuli (e.g., facial expressions and identity), but also to other stimulus properties (e.g., novel vs. familiar). The complexity of these responses suggests that the amygdala is involved in higher-order stimulus processing, and contributes to the extraction of the behavioral significance of stimuli, including emotional salience and valence.

Even within a single subregion such as the BLA, electrophysiological recordings show considerable variability in responses. Distinct populations of neurons in this region were found to respond to fear conditioning (correlating with fear expression) and fear extinction (correlating with extinction performance), respectively (Herry et al., 2008). These two populations furthermore have very different connectivity patterns. 'Fear' neurons receive inputs from the ventral hippocampus, whereas 'extinction' neurons are mainly innervated by medial prefrontal afferents. Although both cell classes project strongly to the medial prefrontal cortex, neurons activated during fear expression predominantly target the prelimbic subregion of the medial prefrontal cortex, while those activated during extinction selectively target the infralimbic subregion (Senn et al., 2014). Note that prelimbic and infralimbic subregions of the medial prefrontal cortex are seen as the rodent homologs of the human dorsal anterior cingulate cortex and ventromedial prefrontal cortex, respectively (Milad \& Quirk, 2012). Direct evidence from network electrophysiology for a role of the amygdala in memory consolidation, however, remains scarce. In the following sections, we will summarize current knowledge about network activity patterns that correlate with memory consolidation and outline the potential role of the amygdala and noradrenergic modulation in these processes.

\section{Replay and the potential role of the amygdala}

Spontaneous reactivation of activity configurations that occurred during prior learning experiences, or replay, is widely seen as a prime candidate for the mechanistic underpinning of memory consolidation (for a review, see O'Neill, Pleydell-Bouverie, Dupret, \& Csicsvari, 2010). Pavlides and Winson (1989) first 
demonstrated that hippocampal 'place' cells (cells that exhibit spatially constrained firing) that had been active during awake exploration showed increased firing rates during subsequent phases of Non-Rapid EyeMovement (NREM) sleep. Such reactivations are coordinated across cell pairs that fired together during recent experiences (Wilson \& McNaughton, 1994), and these pairs were shown to maintain their temporal ordering of activation (Skaggs \& McNaughton, 1996). Lee and Wilson (2002) furthermore showed that hippocampal place cells could replay sequences of firing mirroring the ordered activation that took place as the rat repeatedly traversed place fields of different cells in succession. Simultaneous or sequential ensemble reactivations have also been shown in multiple cortical regions (Euston, Tatsuno, \& McNaughton, 2007; Hoffman \& McNaughton, 2002; Ji \& Wilson, 2007), suggesting that this phenomenon could be a manifestation of the activation of cortex-wide cell assemblies, and in the ventral striatum, a key area for the processing of emotional and reward-related information (Pennartz et al., 2004).

Most studies report sleep replay during NREM sleep (but see, e.g., Louie \& Wilson, 2001), suggesting that the synchronized patterns in that sleep phase are more suited for spontaneous replay. However, simultaneous and sequential assembly activation correlated to previous experience is also present during active behavior, and may subserve memory encoding and online processing of information. This 'awake replay' (Carr, Jadhav, \& Frank, 2011; Karlsson \& Frank, 2009) presents features very similar to sleep replay. Interestingly, in awake replay, sequences may recur both in the original order and in a temporally reversed order (Diba \& Buzsáki, 2007; Foster \& Wilson, 2006), which, based on computational models of reinforcement learning, may be important for learning the relationship between a sequence of actions and the obtained reward. In line with this interpretation, awake replay is enhanced following salient (Cheng \& Frank, 2008) and reward-related (Singer \& Frank, 2009) experiences.

What role could the amygdala play in these processes? One possibility is that amygdala activation during emotionally arousing experiences or at the beginning of a replay sweep contributes to 'gating' and determines which of a number of possible assemblies will reactivate. This way, the amygdala could select behaviorally significant sequences and determine which information is preferentially consolidated, based on salience and valence computations. An alternative scenario is that the amygdala may be recruited as a consequence of inputs from other brain regions or towards the end of a replay sequence, at the point that corresponds to the outcome of the replayed action. This would indicate that amygdala involvement in replay provides information about the valence of a certain outcome. Which of these two possible directions of information flow is predominant (or whether a bi-directional exchange takes place) is not known. Interestingly, it was recently shown that activation of a dentate gyrus cell assembly related to a fear memory is sufficient to cause robust amygdala activation (Ramirez et al., 2013). While this finding is consistent with the second scenario, more research is needed to reach a definite conclusion.

\section{Hippocampal-neocortical communication and the potential role of the amygdala}

Models of systems consolidation propose that the function of spontaneous reactivations of hippocampal cell assemblies during 'offline' states is not merely to strengthen local synaptic modifications. Rather, it is thought that coordinated reactivation across hippocampal-neocortical networks leads to a gradual integration 
of newly acquired information into neocortical networks, which is accompanied by a decrease in hippocampal involvement (Frankland \& Bontempi, 2005; Rasch \& Born, 2007). In offline states, the neocortex and hippocampus are indeed engaged in an intense dialogue, with cortical up and down states and hippocampal sharp waves as the main, inter-dependent components. This dialogue affects how spontaneous cell assembly activations, which embody replay, can interact across the brain. Recent data showed how replay of assembly sequences in the visual cortex and the hippocampus takes place in a coordinated fashion (Ji \& Wilson, 2007), and how replay in the prefrontal cortex takes place with increased probability at the times of occurrence of hippocampal sharp waves (Peyrache, Khamassi, Benchenane, Wiener, \& Battaglia, 2009), demonstrating the influence this hippocampal pattern exerts on cortical activity. In fact, cortical replay also correlates with cortical up states: the average intensity replay covaries with the frequency of up/down state transitions, generating the 'slow waves' of slow wave sleep (Johnson, Euston, Tatsuno, \& McNaughton, 2010). Furthermore, up states appear to act as 'frames' delimiting sequential replay events in visual cortex (Ji \& Wilson, 2007). In the prefrontal cortex during early NREM stages, replay tends to peak at the beginning, and especially at the end of an up-state (Peyrache et al., 2009).

What can be the role of the amygdala in this hippocampal-neocortical exchange? A critical insight about the possible 'enabling' role of the amygdala comes from the work of Paz and Paré (2006), which shows that amygdala activation facilitates the transmission of information from the entorhinal to perirhinal cortex, two areas in the medial temporal lobe that are important for memory formation and mediate communication between the hippocampus and the neocortex (Bauer, Paz, \& Paré, 2007). This communication is normally impeded by strong feedforward inhibition, but simultaneous stimulation of the amygdala and entorhinal cortex relieves this inhibition and permits the activation of perirhinal neurons. This suggests that, by acting on the strategic entorhinal-perirhinal pathway, the amygdala may determine which information passes from the hippocampus to the neocortex.

Additional evidence for the participation of the amygdala in hippocampal-neocortical networks is available from the analysis of oscillatory coherence and synchronization. These are important phenomena because they may determine the structure of the effective network of communication between brain regions: the basic assumption is that when two regions are effectively communicating, they will oscillate at a constant phase lag, which is optimal to favor coherence (Fries, 2005). Incoherent oscillations or suboptimal phase lags will greatly reduce the effect of inputs from one region on another. Most relevant for memory encoding seems to be coherence at the theta range $(6-10 \mathrm{~Hz})$, which has been demonstrated between hippocampus and prefrontal cortex (Adhikari, Topiwala, \& Gordon, 2010; Benchenane et al., 2010; Siapas, Lubenov, \& Wilson, 2005), and between hippocampus and ventral striatum (Lansink, Goltstein, Lankelma, McNaughton, \& Pennartz, 2009). Theta coherence between hippocampus and amygdala has also been demonstrated, in particular during the expression of conditioned fear (Pape, Narayanan, Smid, Stork, \& Seidenbecher, 2005; Seidenbecher, Laxmi, Stork, \& Pape, 2003). Furthermore, increased theta activity between amygdala, hippocampus, and medial prefrontal cortex is observed during Rapid Eye-Movement sleep following the acquisition of a fear memory, and this increase predicts the later expression of the fear memory (Popa, Duvarci, Popescu, Léna, \& Paré, 2010). Coherence in the higher-frequency gamma band (30-100 Hz) has 
also been examined. For instance, interactions within the entorhinal-perirhinal pathway described above were shown to be coordinated by gamma oscillations in a BLA-rhinal network (Bauer et al., 2007). These findings converge with functional connectivity studies in humans described above, which have shown that the amygdala, hippocampus, (ventro)medial prefrontal cortex, and dorsal anterior cingulate cortex are part of large-scale networks (Buckner et al., 2008; Seeley et al., 2007) that are thought to play a role in 'offline' processing and consolidation (Ranganath \& Ritchey, 2012; van Kesteren et al., 2010).

Despite recent progress described in this section, our understanding of the dynamics of amygdala ensembles and their role in memory encoding and consolidation, particularly of learning experiences that are emotionally arousing and associated with noradrenergic activation, remains limited. An important development that may make it possible to disentangle the internal amygdala circuitry is the new tool of optogenetics, which allows for specific manipulation of cell types, nuclei, and connections on a millisecond timescale. While recent studies using this technique concentrate on the modulation of anxiety and motivation (Jennings et al., 2013; Kim et al., 2013), it will be enticing to test the importance of the same connections for the joint modulation of memory by the amygdala (see, e.g., Huff, Miller, Deisseroth, Moorman, \& Lalumiere, 2013) and neuromodulatory structures such as the locus coeruleus (Carter et al., 2010). In line with the modulation hypothesis that has been the starting point of this literature review, the amygdala may engage stress hormone and neurotransmitter systems to achieve the increase in cortical excitability and plasticity necessary to promote memory consolidation across widespread cell assemblies. A promising result in this sense is that noradrenergic neurons in the locus coeruleus continue to fire during NREM sleep, in a pattern that is phase locked to the cortical slow oscillations (Eschenko, Magri, Panzeri, \& Sara, 2012), which is also known to modulate memory replay, and possibly consolidation. Whether this spontaneous activity of the locus coeruleus is at the basis of the noradrenergic control on memory consolidation and how this influences the role of the amygdala in these processes is a question that will need to be explored in future work.

\section{Concluding remarks}

In conclusion, the three research lines reviewed here are just starting to interact closely in a way allowing hypotheses that are jointly tested in a truly interdisciplinary fashion. Aligning pharmacological manipulations, behavioral paradigms, anatomical systems, and analytical tools for assessing neural activity and connectivity across research lines and exploiting specific advantages of each line will help us understanding the neural mechanisms underlying the mnemonic consequences of emotional experiences. This research agenda can be started from a solid set of evidence showing that the amygdala is a critical nexus in large-scale networks underlying emotional memory encoding and consolidation, rather than merely being a storage site. The amygdala modulates neuroplastic processes in widespread neural systems by changing network properties of large-scale neural systems mainly through noradrenergic mechanisms. Analysis of intrinsic connectivity within such networks has identified the hippocampus, the (ventro)medial prefrontal cortex, the anterior cingulate cortex, insula, and striatum as critical constituents of this amygdala-centered circuit. Despite this recent progress several open questions await to be tackled. For example, invasive 
electrophysiology in rodents combined with highly specific interventions, as offered by optogenetic techniques, will enable outlining how the amygdala interacts with these other regions, the directionality of their coupling, and how this coupling reactivates memory representations. Investigating homeostatic and attentional processes at encoding will tell us what the mnemonic function of the salience network is as well as whether and how the default mode network contributes to emotional memory consolidation. Despite the overlap in insight between research lines there are also critical omissions. For instance, human neuroimaging studies have largely ignored consolidation processes until recently (but see Deuker et al., 2013; Staresina, Alink, Kriegeskorte, \& Henson, 2013; Tambini \& Davachi, 2013; Tambini, Ketz, \& Davachi, 2010; van Kesteren et al., 2010), while animal studies often ignored encoding processes. Furthermore, it appears essential to go beyond general processes underlying emotional memory and to understand individual differences explaining why certain individuals are more vulnerable or resilient when confronted with emotional or even traumatic experiences. However, combining insight in general processes and individual differences might one day provide a mechanistic account of mental disorders linked via mnemonic traces to stressful life events that enables mechanistic and individualized treatment.

\section{References}

Abe, K. (2001). Modulation of hippocampal long-term potentiation by the amygdala: a synaptic mechanism linking emotion and memory. Japanese Journal of Pharmacology, 86(1), 18-22.

Adhikari, A., Topiwala, M. A., \& Gordon, J. A. (2010). Synchronized activity between the ventral hippocampus and the medial prefrontal cortex during anxiety. Neuron, 65(2), 257-269.

Adolphs, R. (2003). Cognitive neuroscience of human social behaviour. Nature Reviews Neuroscience, 4(3), $165-178$.

Adolphs, R., Cahill, L., Schul, R., \& Babinsky, R. (1997). Impaired declarative memory for emotional material following bilateral amygdala damage in humans. Learning \& Memory, 4(3), 291-300.

Adolphs, R., Denburg, N. L., \& Tranel, D. (2001). The amygdala's role in long-term declarative memory for gist and detail. Behavioral Neuroscience, 115(5), 983-992.

Adolphs, R., Tranel, D., \& Buchanan, T. W. (2005). Amygdala damage impairs emotional memory for gist but not details of complex stimuli. Nature Neuroscience, 8(4), 512-518.

Aggleton, J. P. (Ed.). (2000). Amygdala: Role in modulation of memory storage. In The amygdala (pp. 391423). London, England: Oxford University Press.

Akirav, I., \& Richter-Levin, G. (1999). Biphasic modulation of hippocampal plasticity by behavioral stress and basolateral amygdala stimulation in the rat. Journal of Neuroscience, 19(23), 10530-10535.

Akirav, I., \& Richter-Levin, G. (2002). Mechanisms of amygdala modulation of hippocampal plasticity. Journal of Neuroscience, 22(22), 9912-9921.

Almaguer-Melian, W., Martínez-Martí, L., Frey, J. U., \& Bergado, J. A. (2003). The amygdala is part of the behavioural reinforcement system modulating long-term potentiation in rat hippocampus. Neuroscience, $119(2), 319-322$.

Arnsten, A. F. T. (2009). Stress signalling pathways that impair prefrontal cortex structure and function. 
Nature Reviews Neuroscience, 10(6), 410-422.

Ashby, F. G., Turner, B. O., \& Horvitz, J. C. (2010). Cortical and basal ganglia contributions to habit learning and automaticity. Trends in Cognitive Sciences, 14(5), 208-215.

Aston-Jones, G., \& Cohen, J. D. (2005). Adaptive gain and the role of the locus coeruleus-norepinephrine system in optimal performance. Journal of Comparative Neurology, 493(1), 99-110.

Atsak, P., Roozendaal, B., \& Campolongo, P. (2012). Role of the endocannabinoid system in regulating glucocorticoid effects on memory for emotional experiences. Neuroscience, 204, 104-116.

Bar, M. (2007). The proactive brain: using analogies and associations to generate predictions. Trends in Cognitive Sciences, 11(7), 280-289.

Barsegyan, A., Mackenzie, S. M., Kurose, B. D., McGaugh, J. L., \& Roozendaal, B. (2010). Glucocorticoids in the prefrontal cortex enhance memory consolidation and impair working memory by a common neural mechanism. Proceedings of the National Academy of Sciences of the United States of America, 107(38), 16655-16660.

Bauer, E. P., Paz, R., \& Paré, D. (2007). Gamma oscillations coordinate amygdalo-rhinal interactions during learning. Journal of Neuroscience, 27(35), 9369-9379.

Bechara, A., Tranel, D., Damasio, H., Adolphs, R., Rockland, C., \& Damasio, A. R. (1995). Double dissociation of conditioning and declarative knowledge relative to the amygdala and hippocampus in humans. Science, 269(5227), 1115-1118.

Benchenane, K., Peyrache, A., Khamassi, M., Tierney, P. L., Gioanni, Y., Battaglia, F. P., \& Wiener, S. I. (2010). Coherent theta oscillations and reorganization of spike timing in the hippocampal- prefrontal network upon learning. Neuron, 66(6), 921-936.

Berlau, D. J., \& McGaugh, J. L. (2006). Enhancement of extinction memory consolidation: the role of the noradrenergic and GABAergic systems within the basolateral amygdala. Neurobiology of Learning and Memory, 86(2), 123-132.

Bianchin, M., Mello e Souza, T., Medina, J. H., \& Izquierdo, I. (1999). The amygdala is involved in the modulation of long-term memory, but not in working or short-term memory. Neurobiology of Learning and Memory, 71(2), 127-131.

Bird, C. M., \& Burgess, N. (2008). The hippocampus and memory: insights from spatial processing. Nature Reviews Neuroscience, 9(3), 182-194.

Borrell, J., de Kloet, E. R., \& Bohus, B. (1984). Corticosterone decreases the efficacy of adrenaline to affect passive avoidance retention of adrenalectomized rats. Life Sciences, 34(1), 99-104.

Borrell, J., de Kloet, E. R., Versteeg, D. H., \& Bohus, B. (1983). Inhibitory avoidance deficit following short-term adrenalectomy in the rat: the role of adrenal catecholamines. Behavioral and Neural Biology, $39(2), 241-258$.

Boyden, E. S., Zhang, F., Bamberg, E., Nagel, G., \& Deisseroth, K. (2005). Millisecond-timescale, genetically targeted optical control of neural activity. Nature Neuroscience, 8(9), 1263-1268.

Breiter, H. C., Etcoff, N. L., Whalen, P. J., Kennedy, W. A., Rauch, S. L., Buckner, R. L., Strauss, M. M., et al. (1996). Response and habituation of the human amygdala during visual processing of facial 
expression. Neuron, 17(5), 875-887.

Buchel, C., Dolan, R. J., Armony, J. L., \& Friston, K. J. (1999). Amygdala-hippocampal involvement in human aversive trace conditioning revealed through event-related functional magnetic resonance imaging. Journal of Neuroscience, 19(24), 10869-10876.

Buckner, R. L., \& Carroll, D. C. (2007). Self-projection and the brain. Trends in Cognitive Sciences, 11(2), $49-57$.

Buckner, R. L., Andrews-Hanna, J. R., \& Schacter, D. L. (2008). The brain's default network: anatomy, function, and relevance to disease. Annals of the New York Academy of Sciences, 1124, 1-38.

Buzsáki, G. (2004). Large-scale recording of neuronal ensembles. Nature Neuroscience, 7(5), 446-451.

Büchel, C., Morris, J., Dolan, R. J., \& Friston, K. J. (1998). Brain systems mediating aversive conditioning: an event-related fMRI study. Neuron, 20(5), 947-957.

Cahill, L., \& Alkire, M. T. (2003). Epinephrine enhancement of human memory consolidation: interaction with arousal at encoding. Neurobiology of Learning and Memory, 79(2), 194-198.

Cahill, L., Babinsky, R., Markowitsch, H. J., \& McGaugh, J. L. (1995). The amygdala and emotional memory. Nature, 377(6547), 295-296.

Cahill, L., Haier, R. J., Fallon, J., Alkire, M. T., Tang, C., Keator, D., Wu, J., et al. (1996). Amygdala activity at encoding correlated with long-term, free recall of emotional information. Proceedings of the National Academy of Sciences of the United States of America, 93(15), 8016-8021.

Cahill, L., Haier, R. J., White, N. S., Fallon, J., Kilpatrick, L., Lawrence, C., Potkin, S. G., et al. (2001). Sexrelated difference in amygdala activity during emotionally influenced memory storage. Neurobiology of Learning and Memory, 75(1), 1-9.

Cahill, L., Prins, B., Weber, M., \& McGaugh, J. L. (1994). Beta-adrenergic activation and memory for emotional events. Nature, 371(6499), 702-704.

Cahill, L., Uncapher, M., Kilpatrick, L., Alkire, M. T., \& Turner, J. (2004). Sex-related hemispheric lateralization of amygdala function in emotionally influenced memory: an FMRI investigation. Learning \& Memory, 11(3), 261-266.

Canli, T., Zhao, Z., Brewer, J., Gabrieli, J. D., \& Cahill, L. (2000). Event-related activation in the human amygdala associates with later memory for individual emotional experience. Journal of Neuroscience, 20(19), RC99.

Carr, M. F., Jadhav, S. P., \& Frank, L. M. (2011). Hippocampal replay in the awake state: a potential substrate for memory consolidation and retrieval. Nature Neuroscience, 14(2), 147-153.

Carter, M. E., Yizhar, O., Chikahisa, S., Nguyen, H., Adamantidis, A., Nishino, S., Deisseroth, K., et al. (2010). Tuning arousal with optogenetic modulation of locus coeruleus neurons. Nature Neuroscience, 13(12), 1526-1533.

Cheng, D. T., Disterhoft, J. F., Power, J. M., Ellis, D. A., \& Desmond, J. E. (2008). Neural substrates underlying human delay and trace eyeblink conditioning. Proceedings of the National Academy of Sciences of the United States of America, 105(23), 8108-8113.

Cheng, D. T., Knight, D. C., Smith, C. N., Stein, E. A., \& Helmstetter, F. J. (2003). Functional MRI of 
human amygdala activity during Pavlovian fear conditioning: Stimulus processing versus response expression. Behavioral Neuroscience, 117(1), 3-10.

Cheng, S., \& Frank, L. M. (2008). New experiences enhance coordinated neural activity in the hippocampus. Neuron, 57(2), 303-313.

Christianson, S. A. (1992). Emotional stress and eyewitness memory: a critical review. Psychological Bulletin, 112(2), 284-309.

Corbetta, M., \& Shulman, G. L. (2002). Control of goal-directed and stimulus-driven attention in the brain. Nature Reviews Neuroscience, 3(3), 201-215.

Corbetta, M., Patel, G., \& Shulman, G. L. (2008). The reorienting system of the human brain: from environment to theory of mind. Neuron, 58(3), 306-324.

Costa-Miserachs, D., Portell-Cortés, I., Aldavert-Vera, L., Torras-García, M., \& Morgado-Bernal, I. (1994). Long-term memory facilitation in rats by posttraining epinephrine. Behavioral Neuroscience, 108(3), 469-474.

Cottrell, G. A., \& Nakajima, S. (1977). Effect of corticosteroids in the hippocampus on passive avoidance behavior in the rat. Pharmacology, Biochemistry, and Behavior, 7(3), 277-280.

Cousijn, H., Rijpkema, M., Qin, S., van Marle, H. J. F., Franke, B., Hermans, E. J., van Wingen, G., et al. (2010). Acute stress modulates genotype effects on amygdala processing in humans. Proceedings of the National Academy of Sciences of the United States of America, 107(21), 9867-9872.

Craig, A. D. B. (2008). How do you feel--now? The anterior insula and human awareness. Nature Reviews Neuroscience, 10(1), 59-70.

Critchley, H. D. (2005). Neural mechanisms of autonomic, affective, and cognitive integration. Journal of Comparative Neurology, 493(1), 154-166.

Damasio, A., \& Carvalho, G. B. (2013). The nature of feelings: evolutionary and neurobiological origins. Nature Reviews Neuroscience, 14(2), 143-152.

Damoiseaux, J. S., Rombouts, S. A. R. B., Barkhof, F., Scheltens, P., Stam, C. J., Smith, S. M., \& Beckmann, C. F. (2006). Consistent resting-state networks across healthy subjects. Proceedings of the National Academy of Sciences of the United States of America, 103(37), 13848-13853.

Davis, M., \& Whalen, P. J. (2000). The amygdala: vigilance and emotion. Molecular Psychiatry, 6(1), 1334.

Deuker, L., Olligs, J., Fell, J., Kranz, T. A., Mormann, F., Montag, C., Reuter, M., et al. (2013). Memory consolidation by replay of stimulus-specific neural activity. Journal of Neuroscience, 33(49), 1937319383. Society for Neuroscience.

Diamond, D. M., Campbell, A. M., Park, C. R., Halonen, J., \& Zoladz, P. R. (2007). The temporal dynamics model of emotional memory processing: a synthesis on the neurobiological basis of stress-induced amnesia, flashbulb and traumatic memories, and the Yerkes-Dodson law. Neural Plasticity, 2007, 60803.

Diba, K., \& Buzsáki, G. (2007). Forward and reverse hippocampal place-cell sequences during ripples. Nature Neuroscience, 10(10), 1241-1242. 
Dolcos, F., Labar, K. S., \& Cabeza, R. (2004). Interaction between the amygdala and the medial temporal lobe memory system predicts better memory for emotional events. Neuron, 42(5), 855-863.

Dosenbach, N. U. F., Fair, D. A., Cohen, A. L., Schlaggar, B. L., \& Petersen, S. E. (2008). A dual-networks architecture of top-down control. Trends in Cognitive Sciences, 12(3), 99-105.

Ellis, M. E., \& Kesner, R. P. (1981). Physostigmine and norepinephrine: effects of injection into the amygdala on taste associations. Physiology \& Behavior, 27(2), 203-209.

Eschenko, O., Magri, C., Panzeri, S., \& Sara, S. J. (2012). Noradrenergic neurons of the locus coeruleus are phase locked to cortical up-down states during sleep. Cerebral Cortex, 22(2), 426-435.

Euston, D. R., Tatsuno, M., \& McNaughton, B. L. (2007). Fast-forward playback of recent memory sequences in prefrontal cortex during sleep. Science, 318(5853), 1147-1150.

Ferry, B., \& McGaugh, J. L. (1999). Clenbuterol administration into the basolateral amygdala post-training enhances retention in an inhibitory avoidance task. Neurobiology of Learning and Memory, 72(1), 8-12.

Foster, D. J., \& Wilson, M. A. (2006). Reverse replay of behavioural sequences in hippocampal place cells during the awake state. Nature, 440(7084), 680-683.

Frankland, P. W., \& Bontempi, B. (2005). The organization of recent and remote memories. Nature Reviews Neuroscience, 6(2), 119-130.

Fredrikson, M., Wik, G., Fischer, H., \& Andersson, J. (1995). Affective and attentive neural networks in humans: a PET study of Pavlovian conditioning. Neuroreport, 7(1), 97-101.

Frey, S., Bergado-Rosado, J., Seidenbecher, T., Pape, H. C., \& Frey, J. U. (2001). Reinforcement of early long-term potentiation (early-LTP) in dentate gyrus by stimulation of the basolateral amygdala: heterosynaptic induction mechanisms of late-LTP. Journal of Neuroscience, 21(10), 3697-3703.

Fries, P. (2005). A mechanism for cognitive dynamics: neuronal communication through neuronal coherence. Trends in Cognitive Sciences, 9(10), 474-480.

Gallagher, M., Kapp, B. S., Pascoe, P. J., \& Rapp, P. R. (1981). A neuropharmacology of amygdaloid systems which contribute to learning and memory. In The amygdaloid complex (pp. 343-354). Amsterdam: Elsevier/North-Holland.

Galvez, R., Mesches, M. H., \& McGaugh, J. L. (1996). Norepinephrine release in the amygdala in response to footshock stimulation. Neurobiology of Learning and Memory, 66(3), 253-257.

Gerard, R. W. (1961). The fixation of experience. In Brain mechanisms and learning (pp. 21-35). Springfield, IL: Charles C. Thomas.

Gold, P. E. (2004). Coordination of multiple memory systems. Neurobiology of Learning and Memory, $82(3), 230-242$.

Gold, P. E., \& Van Buskirk, R. B. (1975). Facilitation of time-dependent memory processes with posttrial epinephrine injections. Behavioral Biology, 13(2), 145-153.

Gothard, K. M., Battaglia, F. P., Erickson, C. A., Spitler, K. M., \& Amaral, D. G. (2007). Neural responses to facial expression and face identity in the monkey amygdala. Journal of Neurophysiology, 97(2), 1671-1683.

Greicius, M. D., Krasnow, B., Reiss, A. L., \& Menon, V. (2003). Functional connectivity in the resting 
brain: a network analysis of the default mode hypothesis. Proceedings of the National Academy of Sciences of the United States of America, 100(1), 253-258.

Guzowski, J. F., Lyford, G. L., Stevenson, G. D., Houston, F. P., McGaugh, J. L., Worley, P. F., \& Barnes, C. A. (2000). Inhibition of activity-dependent arc protein expression in the rat hippocampus impairs the maintenance of long-term potentiation and the consolidation of long-term memory. Journal of Neuroscience, 20(11), 3993-4001.

Hamann, S. B., Ely, T. D., Grafton, S. T., \& Kilts, C. D. (1999). Amygdala activity related to enhanced memory for pleasant and aversive stimuli. Nature Neuroscience, 2(3), 289-293.

Hatfield, T., \& McGaugh, J. L. (1999). Norepinephrine infused into the basolateral amygdala posttraining enhances retention in a spatial water maze task. Neurobiology of Learning and Memory, 71(2), 232-239.

Hatfield, T., Spanis, C., \& McGaugh, J. L. (1999). Response of amygdalar norepinephrine to footshock and GABAergic drugs using in vivo microdialysis and HPLC. Brain Research, 835(2), 340-345.

Henckens, M. J. A. G., Hermans, E. J., Pu, Z., Joëls, M., \& Fernández, G. (2009). Stressed memories: how acute stress affects memory formation in humans. Journal of Neuroscience, 29(32), 10111-10119.

Henckens, M. J. A. G., van Wingen, G. A., Joëls, M., \& Fernández, G. (2010). Time-dependent effects of corticosteroids on human amygdala processing. Journal of Neuroscience, 30(38), 12725-12732.

Henke, K. (2010). A model for memory systems based on processing modes rather than consciousness. Nature Reviews Neuroscience, 11(7), 523-532.

Hermans, E. J., van Marle, H. J. F., Ossewaarde, L., Henckens, M. J. A. G., Qin, S., van Kesteren, M. T. R., Schoots, V. C., et al. (2011). Stress-related noradrenergic activity prompts large-scale neural network reconfiguration. Science, 334(6059), 1151-1153.

Herry, C., Ciocchi, S., Senn, V., Demmou, L., Müller, C., \& Lüthi, A. (2008). Switching on and off fear by distinct neuronal circuits. Nature, 454(7204), 600-606.

Hoffman, K. L., \& McNaughton, B. L. (2002). Coordinated reactivation of distributed memory traces in primate neocortex. Science, 297(5589), 2070-2073.

Hsu, E. H., Schroeder, J. P., \& Packard, M. G. (2002). The amygdala mediates memory consolidation for an amphetamine conditioned place preference. Behavioural Brain Research, 129(1-2), 93-100.

Huff, M. L., Miller, R. L., Deisseroth, K., Moorman, D. E., \& Lalumiere, R. T. (2013). Posttraining optogenetic manipulations of basolateral amygdala activity modulate consolidation of inhibitory avoidance memory in rats. Proceedings of the National Academy of Sciences of the United States of America, 110(9), 3597-3602.

Huff, N. C., Frank, M., Wright-Hardesty, K., Sprunger, D., Matus-Amat, P., Higgins, E., \& Rudy, J. W. (2006). Amygdala regulation of immediate-early gene expression in the hippocampus induced by contextual fear conditioning. Journal of Neuroscience, 26(5), 1616-1623.

Huff, N. C., Wright-Hardesty, K. J., Higgins, E. A., Matus-Amat, P., \& Rudy, J. W. (2005). Context preexposure obscures amygdala modulation of contextual-fear conditioning. Learning \& Memory, 12(5), 456-460.

Hugdahl, K., Berardi, A., Thompson, W. L., Kosslyn, S. M., Macy, R., Baker, D. P., Alpert, N. M., et al. 
(1995). Brain mechanisms in human classical conditioning: a PET blood flow study. Neuroreport, 6(13), 1723-1728.

Hui, G. K., Figueroa, I. R., Poytress, B. S., Roozendaal, B., McGaugh, J. L., \& Weinberger, N. M. (2004). Memory enhancement of classical fear conditioning by post-training injections of corticosterone in rats. Neurobiology of Learning and Memory, 81(1), 67-74.

Hurlemann, R., Walter, H., Rehme, A. K., Kukolja, J., Santoro, S. C., Schmidt, C., Schnell, K., et al. (2010). Human amygdala reactivity is diminished by the $\beta$-noradrenergic antagonist propranolol. Psychological Medicine, 40(11), 1839-1848.

Ikegaya, Y., Nakanishi, K., Saito, H., \& Abe, K. (1997). Amygdala beta-noradrenergic influence on hippocampal long-term potentiation in vivo. Neuroreport, 8(14), 3143-3146.

Ikegaya, Y., Saito, H., \& Abe, K. (1994). Attenuated hippocampal long-term potentiation in basolateral amygdala-lesioned rats. Brain Research, 656(1), 157-164.

Ikegaya, Y., Saito, H., \& Abe, K. (1995). Requirement of basolateral amygdala neuron activity for the induction of long-term potentiation in the dentate gyrus in vivo. Brain Research, 671(2), 351-354.

Introini-Collison, I. B., \& McGaugh, J. L. (1986). Epinephrine modulates long-term retention of an aversively motivated discrimination. Behavioral and Neural Biology, 45(3), 358-365.

Introini-Collison, I. B., Dalmaz, C., \& McGaugh, J. L. (1996). Amygdala beta-noradrenergic influences on memory storage involve cholinergic activation. Neurobiology of Learning and Memory, 65(1), 57-64.

Introini-Collison, I. B., Miyazaki, B., \& McGaugh, J. L. (1991). Involvement of the amygdala in the memory-enhancing effects of clenbuterol. Psychopharmacology, 104(4), 541-544.

Introini-Collison, I. B., Nagahara, A. H., \& McGaugh, J. L. (1989). Memory enhancement with intraamygdala post-training naloxone is blocked by concurrent administration of propranolol. Brain Research, 476(1), 94-101.

Introini-Collison, I., Saghafi, D., Novack, G. D., \& McGaugh, J. L. (1992). Memory-enhancing effects of post-training dipivefrin and epinephrine: involvement of peripheral and central adrenergic receptors. Brain Research, 572(1-2), 81-86.

Izquierdo, I., \& Graudenz, M. (1980). Memory facilitation by naloxone is due to release of dopaminergic and beta-adrenergic systems from tonic inhibition. Psychopharmacology, 67(3), 265-268.

Izquierdo, I., \& Medina, J. H. (1997). Memory formation: the sequence of biochemical events in the hippocampus and its connection to activity in other brain structures. Neurobiology of Learning and Memory, 68(3), 285-316.

Izquierdo, I., Quillfeldt, J. A., Zanatta, M. S., Quevedo, J., Schaeffer, E., Schmitz, P. K., \& Medina, J. H. (1997). Sequential role of hippocampus and amygdala, entorhinal cortex and parietal cortex in formation and retrieval of memory for inhibitory avoidance in rats. European Journal of Neuroscience, 9(4), 786793.

Jennings, J. H., Sparta, D. R., Stamatakis, A. M., Ung, R. L., Pleil, K. E., Kash, T. L., \& Stuber, G. D. (2013). Distinct extended amygdala circuits for divergent motivational states. Nature, 496(7444), 224 228. 
Ji, D., \& Wilson, M. A. (2007). Coordinated memory replay in the visual cortex and hippocampus during sleep. Nature Neuroscience, 10(1), 100-107.

Joëls, M., \& Baram, T. Z. (2009). The neuro-symphony of stress. Nature Reviews Neuroscience, 10(6), 459466.

Joëls, M., Fernández, G., \& Roozendaal, B. (2011). Stress and emotional memory: a matter of timing. Trends in Cognitive Sciences, 15(6), 280-288.

Johnson, L. A., Euston, D. R., Tatsuno, M., \& McNaughton, B. L. (2010). Stored-trace reactivation in rat prefrontal cortex is correlated with down-to-up state fluctuation density. Journal of Neuroscience, 30(7), 2650-2661.

Kalisch, R., Korenfeld, E., Stephan, K. E., Weiskopf, N., Seymour, B., \& Dolan, R. J. (2006). Contextdependent human extinction memory is mediated by a ventromedial prefrontal and hippocampal network. Journal of Neuroscience, 26(37), 9503-9511.

Karlsson, M. P., \& Frank, L. M. (2009). Awake replay of remote experiences in the hippocampus. Nature Neuroscience, 12(7), 913-918.

Kawahara, Y., Hesselink, M. B., van Scharrenburg, G., \& Westerink, B. H. C. (2004). Tonic inhibition by orphanin $\mathrm{FQ} /$ nociceptin of noradrenaline neurotransmission in the amygdala. European Journal of Pharmacology, 485(1-3), 197-200.

Kensinger, E. A., \& Corkin, S. (2004). Two routes to emotional memory: distinct neural processes for valence and arousal. Proceedings of the National Academy of Sciences of the United States of America, 101(9), 3310-3315.

Kesner, R. P., \& Ellis, M. E. (1983). Memory consolidation: brain region and neurotransmitter specificity. Neuroscience Letters, 39(3), 295-300.

Kilpatrick, L., \& Cahill, L. (2003a). Modulation of memory consolidation for olfactory learning by reversible inactivation of the basolateral amygdala. Behavioral Neuroscience, 117(1), 184-188.

Kilpatrick, L., \& Cahill, L. (2003b). Amygdala modulation of parahippocampal and frontal regions during emotionally influenced memory storage. NeuroImage, 20(4), 2091-2099.

Kim, S.-Y., Adhikari, A., Lee, S. Y., Marshel, J. H., Kim, C. K., Mallory, C. S., Lo, M., et al. (2013). Diverging neural pathways assemble a behavioural state from separable features in anxiety. Nature, 496(7444), 219-223.

Klüver, H., \& Bucy, P. C. (1937). "Psychic blindness" and other symptoms following bilateral temporal lobectomy in Rhesus monkeys. American Journal of Physiology, 119, 352-353.

Kober, H., Barrett, L. F., Joseph, J., Bliss-Moreau, E., Lindquist, K., \& Wager, T. D. (2008). Functional grouping and cortical-subcortical interactions in emotion: a meta-analysis of neuroimaging studies. NeuroImage, 42(2), 998-1031.

Kukolja, J., Schläpfer, T. E., Keysers, C., Klingmüller, D., Maier, W., Fink, G. R., \& Hurlemann, R. (2008). Modeling a negative response bias in the human amygdala by noradrenergic-glucocorticoid interactions. Journal of Neuroscience, 28(48), 12868-12876.

LaBar, K. S., \& Phelps, E. A. (1998). Arousal-Mediated Memory Consolidation: Role of the Medial 
Temporal Lobe in Humans. Psychological Science, 9(6), 490-493.

LaBar, K. S., Gatenby, J. C., Gore, J. C., LeDoux, J. E., \& Phelps, E. A. (1998). Human amygdala activation during conditioned fear acquisition and extinction: a mixed-trial fMRI study. Neuron, 20(5), 937-945.

LaBar, K. S., LeDoux, J. E., Spencer, D. D., \& Phelps, E. A. (1995). Impaired fear conditioning following unilateral temporal lobectomy in humans. Journal of Neuroscience, 15(10), 6846-6855.

Lalumiere, R. T., Buen, T.-V., \& McGaugh, J. L. (2003). Post-training intra-basolateral amygdala infusions of norepinephrine enhance consolidation of memory for contextual fear conditioning. Journal of Neuroscience, 23(17), 6754-6758.

Lalumiere, R. T., Nawar, E. M., \& McGaugh, J. L. (2005). Modulation of memory consolidation by the basolateral amygdala or nucleus accumbens shell requires concurrent dopamine receptor activation in both brain regions. Learning \& Memory, 12(3), 296-301.

Lansink, C. S., Goltstein, P. M., Lankelma, J. V., McNaughton, B. L., \& Pennartz, C. M. A. (2009). Hippocampus leads ventral striatum in replay of place-reward information. PLoS Biology, 7(8), e1000173.

LeDoux, J. E. (2000). Emotion circuits in the brain. Annual Review of Neuroscience, 23, 155-184.

Lee, A. K., \& Wilson, M. A. (2002). Memory of sequential experience in the hippocampus during slow wave sleep. Neuron, 36(6), 1183-1194.

Lee, E. H., Lee, C. P., Wang, H. I., \& Lin, W. R. (1993). Hippocampal CRF, NE, and NMDA system interactions in memory processing in the rat. Synapse, 14(2), 144-153.

Liang, K. C. (2001). Epinephrine modulation of memory: Amygdala activation and regulation of long-term memory storage. In P. E. Gold \& W. T. Greenough (Eds.), Memory consolidation: Essays in honor of James L. Mcgaugh (pp. 165-183). Washington, DC, US: American Psychological Association.

Liang, K. C., Chen, L. L., \& Huang, T. E. (1995). The role of amygdala norepinephrine in memory formation: involvement in the memory enhancing effect of peripheral epinephrine. Chinese Journal of Physiology, 38(2), 81-91.

Liang, K. C., Hu, S. J., \& Chang, S. C. (1996). Formation and retrieval of inhibitory avoidance memory: differential roles of glutamate receptors in the amygdala and medial prefrontal cortex. Chinese Journal of Physiology, 39(3), 155-166.

Liang, K. C., Juler, R. G., \& McGaugh, J. L. (1986). Modulating effects of posttraining epinephrine on memory: involvement of the amygdala noradrenergic system. Brain Research, 368(1), 125-133.

Liang, K. C., McGaugh, J. L., \& Yao, H. Y. (1990). Involvement of amygdala pathways in the influence of post-training intra-amygdala norepinephrine and peripheral epinephrine on memory storage. Brain Research, 508(2), 225-233.

Louie, K., \& Wilson, M. A. (2001). Temporally structured replay of awake hippocampal ensemble activity during rapid eye movement sleep. Neuron, 29(1), 145-156.

Lupien, S., Maheu, F., Tu, M., Fiocco, A., \& Schramek, T. (2007). The effects of stress and stress hormones on human cognition: Implications for the field of brain and cognition. Brain and Cognition, 65(3), 209237. 
Malin, E. L., Ibrahim, D. Y., Tu, J. W., \& McGaugh, J. L. (2007). Involvement of the rostral anterior cingulate cortex in consolidation of inhibitory avoidance memory: interaction with the basolateral amygdala. Neurobiology of Learning and Memory, 87(2), 295-302.

Markowitsch, H. J., Calabrese, P., Würker, M., Durwen, H. F., Kessler, J., Babinsky, R., Brechtelsbauer, D., et al. (1994). The amygdala's contribution to memory--a study on two patients with Urbach-Wiethe disease. Neuroreport, 5(11), 1349-1352.

Marschner, A., Kalisch, R., Vervliet, B., Vansteenwegen, D., \& Büchel, C. (2008). Dissociable roles for the hippocampus and the amygdala in human cued versus context fear conditioning. Journal of Neuroscience, 28(36), 9030-9036.

McDonald, A. J. (1991). Organization of amygdaloid projections to the prefrontal cortex and associated striatum in the rat. Neuroscience, 44(1), 1-14.

McDonald, R. J., \& White, N. M. (1993). A triple dissociation of memory systems: hippocampus, amygdala, and dorsal striatum. Behavioral Neuroscience, 107(1), 3-22.

McGaugh, J. L. (1989). Involvement of hormonal and neuromodulatory systems in the regulation of memory storage. Annual Review of Neuroscience, 12, 255-287.

McGaugh, J. L. (2002). Memory consolidation and the amygdala: a systems perspective. Trends in Neurosciences, 25(9), 456.

McGaugh, J. L. (2004). The amygdala modulates the consolidation of memories of emotionally arousing experiences. Annual Review of Neuroscience, 27, 1-28.

McGaugh, J. L., \& Izquierdo, I. (2000). The contribution of pharmacology to research on the mechanisms of memory formation. Trends in Pharmacological Sciences, 21(6), 208-210.

McGaugh, J. L., \& Roozendaal, B. (2002). Role of adrenal stress hormones in forming lasting memories in the brain. Current Opinion in Neurobiology, 12(2), 205-210.

McGaugh, J. L., Introini-Collison, I. B., \& Nagahara, A. H. (1988). Memory-enhancing effects of posttraining naloxone: involvement of beta-noradrenergic influences in the amygdaloid complex. Brain Research, 446(1), 37-49.

McIntyre, C. K., Hatfield, T., \& McGaugh, J. L. (2002). Amygdala norepinephrine levels after training predict inhibitory avoidance retention performance in rats. European Journal of Neuroscience, 16(7), $1223-1226$.

McIntyre, C. K., Miyashita, T., Setlow, B., Marjon, K. D., Steward, O., Guzowski, J. F., \& McGaugh, J. L. (2005). Memory-influencing intra-basolateral amygdala drug infusions modulate expression of Arc protein in the hippocampus. Proceedings of the National Academy of Sciences of the United States of America, 102(30), 10718-10723.

McReynolds, J. R., Donowho, K., Abdi, A., McGaugh, J. L., Roozendaal, B., \& McIntyre, C. K. (2010). Memory-enhancing corticosterone treatment increases amygdala norepinephrine and Arc protein expression in hippocampal synaptic fractions. Neurobiology of Learning and Memory, 93(3), 312-321.

Menon, V. (2011). Large-scale brain networks and psychopathology: a unifying triple network model. Trends in Cognitive Sciences, 15(10), 483-506. 
Menon, V., \& Uddin, L. Q. (2010). Saliency, switching, attention and control: a network model of insula function. Brain Structure and Function, 214(5-6), 655-667.

Milad, M. R., \& Quirk, G. J. (2012). Fear extinction as a model for translational neuroscience: ten years of progress. Annual Review of Psychology, 63, 129-151.

Miranda, M. I., \& McGaugh, J. L. (2004). Enhancement of inhibitory avoidance and conditioned taste aversion memory with insular cortex infusions of 8-Br-cAMP: involvement of the basolateral amygdala. Learning \& Memory, 11(3), 312-317.

Miranda, M. I., LaLumiere, R. T., Buen, T. V., Bermudez-Rattoni, F., \& McGaugh, J. L. (2003). Blockade of noradrenergic receptors in the basolateral amygdala impairs taste memory. European Journal of Neuroscience, 18(9), 2605-2610.

Miranda, M. I., Quirarte, G. L., Rodriguez-Garcia, G., McGaugh, J. L., \& Roozendaal, B. (2008). Glucocorticoids enhance taste aversion memory via actions in the insular cortex and basolateral amygdala. Learning \& Memory, 15(7), 468-476.

Miserendino, M. J., Sananes, C. B., Melia, K. R., \& Davis, M. (1990). Blocking of acquisition but not expression of conditioned fear-potentiated startle by NMDA antagonists in the amygdala. Nature, 345(6277), 716-718.

Morris, J. S., Friston, K. J., \& Dolan, R. J. (1998). Experience-dependent modulation of tonotopic neural responses in human auditory cortex. Proceedings of the Royal Society of London. Series B: Biological Sciences, 265(1397), 649-657.

Morris, J. S., Frith, C. D., Perrett, D. I., Rowland, D., Young, A. W., Calder, A. J., \& Dolan, R. J. (1996). A differential neural response in the human amygdala to fearful and happy facial expressions. Nature, 383(6603), 812-815.

Mosher, C. P., Zimmerman, P. E., \& Gothard, K. M. (2010). Response characteristics of basolateral and centromedial neurons in the primate amygdala. Journal of Neuroscience, 30(48), 16197-16207.

Nater, U. M., \& Rohleder, N. (2009). Salivary alpha-amylase as a non-invasive biomarker for the sympathetic nervous system: Current state of research. Psychoneuroendocrinology, 34(4), 486-496.

O'Neill, J., Pleydell-Bouverie, B., Dupret, D., \& Csicsvari, J. (2010). Play it again: reactivation of waking experience and memory. Trends in Neurosciences, 33(5), 220-229.

Okuda, S., Roozendaal, B., \& McGaugh, J. L. (2004). Glucocorticoid effects on object recognition memory require training-associated emotional arousal. Proceedings of the National Academy of Sciences of the United States of America, 101(3), 853-858.

Onur, O. A., Walter, H., Schlaepfer, T. E., Rehme, A. K., Schmidt, C., Keysers, C., Maier, W., et al. (2009). Noradrenergic enhancement of amygdala responses to fear. Social Cognitive and Affective Neuroscience, 4(2), 119-126.

Packard, M. G., \& Cahill, L. (2001). Affective modulation of multiple memory systems. Current Opinion in Neurobiology, 11(6), 752-756.

Packard, M. G., \& Chen, S. A. (1999). The basolateral amygdala is a cofactor in memory enhancement produced by intrahippocampal glutamate injections. Psychobiology, 27(3), 377-385. Psychonomic 
Society.

Packard, M. G., \& Knowlton, B. J. (2002). Learning and memory functions of the Basal Ganglia. Annual Review of Neuroscience, 25, 563-593.

Packard, M. G., \& McGaugh, J. L. (1992). Double dissociation of fornix and caudate nucleus lesions on acquisition of two water maze tasks: further evidence for multiple memory systems. Behavioral Neuroscience, 106(3), 439-446.

Packard, M. G., \& McGaugh, J. L. (1996). Inactivation of hippocampus or caudate nucleus with lidocaine differentially affects expression of place and response learning. Neurobiology of Learning and Memory, 65(1), 65-72.

Packard, M. G., \& Teather, L. A. (1998). Amygdala modulation of multiple memory systems: hippocampus and caudate-putamen. Neurobiology of Learning and Memory, 69(2), 163-203.

Packard, M. G., Cahill, L., \& McGaugh, J. L. (1994). Amygdala modulation of hippocampal-dependent and caudate nucleus-dependent memory processes. Proceedings of the National Academy of Sciences of the United States of America, 91(18), 8477-8481.

Pape, H.-C., Narayanan, R. T., Smid, J., Stork, O., \& Seidenbecher, T. (2005). Theta activity in neurons and networks of the amygdala related to long-term fear memory. Hippocampus, 15(7), 874-880.

Paré, D., \& Gaudreau, H. (1996). Projection cells and interneurons of the lateral and basolateral amygdala: distinct firing patterns and differential relation to theta and delta rhythms in conscious cats. Journal of Neuroscience, 16(10), 3334-3350.

Paré, D., Dong, J., \& Gaudreau, H. (1995). Amygdalo-entorhinal relations and their reflection in the hippocampal formation: generation of sharp sleep potentials. Journal of Neuroscience, 15(3), 24822503.

Parent, M. B., \& McGaugh, J. L. (1994). Posttraining infusion of lidocaine into the amygdala basolateral complex impairs retention of inhibitory avoidance training. Brain Research, 661(1-2), 97-103.

Pavlides, C., \& Winson, J. (1989). Influences of hippocampal place cell firing in the awake state on the activity of these cells during subsequent sleep episodes. Journal of Neuroscience, 9(8), 2907-2918.

Paz, R., Pelletier, J. G., Bauer, E. P., \& Paré, D. (2006). Emotional enhancement of memory via amygdaladriven facilitation of rhinal interactions. Nature Neuroscience, 9(10), 1321-1329.

Pennartz, C. M. A., Lee, E., Verheul, J., Lipa, P., Barnes, C. A., \& McNaughton, B. L. (2004). The ventral striatum in off-line processing: ensemble reactivation during sleep and modulation by hippocampal ripples. Journal of Neuroscience, 24(29), 6446-6456.

Peper, M., Karcher, S., Wohlfarth, R., Reinshagen, G., \& LeDoux, J. E. (2001). Aversive learning in patients with unilateral lesions of the amygdala and hippocampus. Biological Psychology, 58(1), 1-23.

Petrovich, G. D., Canteras, N. S., \& Swanson, L. W. (2001). Combinatorial amygdalar inputs to hippocampal domains and hypothalamic behavior systems. Brain Research Reviews, 38(1-2), 247-289.

Peyrache, A., Khamassi, M., Benchenane, K., Wiener, S. I., \& Battaglia, F. P. (2009). Replay of rulelearning related neural patterns in the prefrontal cortex during sleep. Nature Neuroscience, 12(7), 919926. 
Pérez-Jaranay, J. M., \& Vives, F. (1991). Electrophysiological study of the response of medial prefrontal cortex neurons to stimulation of the basolateral nucleus of the amygdala in the rat. Brain Research, 564(1), 97-101.

Phelps, E. A. (2004). Human emotion and memory: interactions of the amygdala and hippocampal complex. Current Opinion in Neurobiology, 14(2), 198-202.

Phelps, E. A., \& LeDoux, J. E. (2005). Contributions of the amygdala to emotion processing: from animal models to human behavior. Neuron, 48(2), 175-187.

Pikkarainen, M., Rönkkö, S., Savander, V., Insausti, R., \& Pitkänen, A. (1999). Projections from the lateral, basal, and accessory basal nuclei of the amygdala to the hippocampal formation in rat. Journal of Comparative Neurology, 403(2), 229-260.

Popa, D., Duvarci, S., Popescu, A. T., Léna, C., \& Paré, D. (2010). Coherent amygdalocortical theta promotes fear memory consolidation during paradoxical sleep. Proceedings of the National Academy of Sciences of the United States of America, 107(14), 6516-6519.

Popescu, A. T., Popa, D., \& Paré, D. (2009). Coherent gamma oscillations couple the amygdala and striatum during learning. Nature Neuroscience, 12(6), 801-807.

Popescu, A. T., Saghyan, A. A., \& Paré, D. (2007). NMDA-dependent facilitation of corticostriatal plasticity by the amygdala. Proceedings of the National Academy of Sciences of the United States of America, 104(1), 341-346.

Preston, A. R., \& Eichenbaum, H. (2013). Interplay of hippocampus and prefrontal review cortex in memory. Current Biology, 23(17), R764-R773. Elsevier.

Qin, S., Hermans, E. J., van Marle, H. J. F., \& Fernández, G. (2012). Understanding low reliability of memories for neutral information encoded under stress: Alterations in memory-related activation in the hippocampus and midbrain. Journal of Neuroscience, 32(12), 4032-4041.

Qin, S., van Marle, H. J. F., Hermans, E. J., \& Fernández, G. (2011). Subjective sense of memory strength and the objective amount of information accurately remembered are related to distinct neural correlates at encoding. Journal of Neuroscience, 31(24), 8920-8927.

Qin, Y. L., McNaughton, B. L., Skaggs, W. E., \& Barnes, C. A. (1997). Memory reprocessing in corticocortical and hippocampocortical neuronal ensembles. Philosophical transactions of the Royal Society of London Series B, Biological sciences, 352(1360), 1525-1533.

Quillfeldt, J. A., Zanatta, M. S., Schmitz, P. K., Quevedo, J., Schaeffer, E., Lima, J. B., Medina, J. H., et al. (1996). Different brain areas are involved in memory expression at different times from training. Neurobiology of Learning and Memory, 66(2), 97-101.

Quirarte, G. L., Galvez, R., Roozendaal, B., \& McGaugh, J. L. (1998). Norepinephrine release in the amygdala in response to footshock and opioid peptidergic drugs. Brain Research, 808(2), 134-140.

Quirarte, G. L., Roozendaal, B., \& McGaugh, J. L. (1997). Glucocorticoid enhancement of memory storage involves noradrenergic activation in the basolateral amygdala. Proceedings of the National Academy of Sciences of the United States of America, 94(25), 14048-14053.

Raichle, M. E. (2009). A paradigm shift in functional brain imaging. Journal of Neuroscience, 29(41), 
$12729-12734$.

Raichle, M. E., \& Snyder, A. Z. (2007). A default mode of brain function: a brief history of an evolving idea. NeuroImage, 37(4), 1083-1090.

Raichle, M. E., MacLeod, A. M., Snyder, A. Z., Powers, W. J., Gusnard, D. A., \& Shulman, G. L. (2001). A default mode of brain function. Proceedings of the National Academy of Sciences of the United States of America, 98(2), 676-682.

Ramirez, S., Liu, X., Lin, P.-A., Suh, J., Pignatelli, M., Redondo, R. L., Ryan, T. J., et al. (2013). Creating a false memory in the hippocampus. Science, 341(6144), 387-391.

Ranganath, C., \& Ritchey, M. (2012). Two cortical systems for memory-guided behaviour. Nature Reviews Neuroscience, 13(10), 713-726.

Rasch, B., \& Born, J. (2007). Maintaining memories by reactivation. Current Opinion in Neurobiology, 17(6), 698-703.

Rasch, B., Spalek, K., Buholzer, S., Luechinger, R., Boesiger, P., Papassotiropoulos, A., \& de Quervain, D. J.-F. (2009). A genetic variation of the noradrenergic system is related to differential amygdala activation during encoding of emotional memories. Proceedings of the National Academy of Sciences of the United States of America, 106(45), 19191-19196.

Richardson, M. P., Strange, B. A., \& Dolan, R. J. (2004). Encoding of emotional memories depends on amygdala and hippocampus and their interactions. Nature Neuroscience, 7(3), 278-285.

Roesler, R., Roozendaal, B., \& McGaugh, J. L. (2002). Basolateral amygdala lesions block the memoryenhancing effect of 8-Br-cAMP infused into the entorhinal cortex of rats after training. European Journal of Neuroscience, 15(5), 905-910.

Rogan, M. T., Stäubli, U. V., \& LeDoux, J. E. (1997). Fear conditioning induces associative long-term potentiation in the amygdala. Nature, 390(6660), 604-607.

Roozendaal, B. (2007). Norepinephrine and long-term memory function. In G. A. Ordway, M. A. Schwartz, $\&$ A. Frazer (Eds.), Brain norepinephrine: Neurobiology and therapeutics. (pp. 236-274). Cambridge: Cambridge University Press.

Roozendaal, B., \& McGaugh, J. L. (1996). Amygdaloid nuclei lesions differentially affect glucocorticoidinduced memory enhancement in an inhibitory avoidance task. Neurobiology of Learning and Memory, $65(1), 1-8$.

Roozendaal, B., \& McGaugh, J. L. (2011). Memory modulation. Behavioral Neuroscience, 125(6), 797-824.

Roozendaal, B., Carmi, O., \& McGaugh, J. L. (1996). Adrenocortical suppression blocks the memoryenhancing effects of amphetamine and epinephrine. Proceedings of the National Academy of Sciences of the United States of America, 93(4), 1429-1433.

Roozendaal, B., Castello, N. A., Vedana, G., Barsegyan, A., \& McGaugh, J. L. (2008). Noradrenergic activation of the basolateral amygdala modulates consolidation of object recognition memory. Neurobiology of Learning and Memory, 90(3), 576-579.

Roozendaal, B., Hahn, E. L., Nathan, S. V., de Quervain, D. J.-F., \& McGaugh, J. L. (2004a). Glucocorticoid effects on memory retrieval require concurrent noradrenergic activity in the hippocampus and 
basolateral amygdala. Journal of Neuroscience, 24(37), 8161-8169.

Roozendaal, B., Hui, G. K., Hui, I. R., Berlau, D. J., McGaugh, J. L., \& Weinberger, N. M. (2006a). Basolateral amygdala noradrenergic activity mediates corticosterone-induced enhancement of auditory fear conditioning. Neurobiology of Learning and Memory, 86(3), 249-255.

Roozendaal, B., McEwen, B. S., \& Chattarji, S. (2009a). Stress, memory and the amygdala. Nature Reviews Neuroscience, 10(6), 423-433.

Roozendaal, B., McReynolds, J. R., \& McGaugh, J. L. (2004b). The basolateral amygdala interacts with the medial prefrontal cortex in regulating glucocorticoid effects on working memory impairment. Journal of Neuroscience, 24(6), 1385-1392.

Roozendaal, B., McReynolds, J. R., van der Zee, E. A., Lee, S., McGaugh, J. L., \& McIntyre, C. K. (2009b). Glucocorticoid effects on memory consolidation depend on functional interactions between the medial prefrontal cortex and basolateral amygdala. Journal of Neuroscience, 29(45), 14299-14308.

Roozendaal, B., Okuda, S., van der Zee, E. A., \& McGaugh, J. L. (2006b). Glucocorticoid enhancement of memory requires arousal-induced noradrenergic activation in the basolateral amygdala. Proceedings of the National Academy of Sciences of the United States of America, 103(17), 6741-6746.

Rosenkranz, J. A., \& Grace, A. A. (2002). Cellular mechanisms of infralimbic and prelimbic prefrontal cortical inhibition and dopaminergic modulation of basolateral amygdala neurons in vivo. Journal of Neuroscience, 22(1), 324-337.

Runyan, J. D., \& Dash, P. K. (2004). Intra-medial prefrontal administration of SCH-23390 attenuates ERK phosphorylation and long-term memory for trace fear conditioning in rats. Neurobiology of Learning and Memory, 82(2), 65-70.

Sacchetti, B., Lorenzini, C. A., Baldi, E., Tassoni, G., \& Bucherelli, C. (1999). Auditory thalamus, dorsal hippocampus, basolateral amygdala, and perirhinal cortex role in the consolidation of conditioned freezing to context and to acoustic conditioned stimulus in the rat. Journal of Neuroscience, 19(21), 9570-9578.

Sadaghiani, S., Scheeringa, R., Lehongre, K., Morillon, B., Giraud, A.-L., \& Kleinschmidt, A. (2010). Intrinsic connectivity networks, alpha oscillations, and tonic alertness: a simultaneous electroencephalography/functional magnetic resonance imaging study. Journal of Neuroscience, 30(30), $10243-10250$.

Salinas, J. A., Introini-Collison, I. B., Dalmaz, C., \& McGaugh, J. L. (1997). Posttraining intraamygdala infusions of oxotremorine and propranolol modulate storage of memory for reductions in reward magnitude. Neurobiology of Learning and Memory, 68(1), 51-59.

Sandi, C., \& Pinelo-Nava, M. T. (2007). Stress and memory: Behavioral effects and neurobiological mechanisms. Neural Plasticity, 2007, 1-21.

Sara, S. J., \& Bouret, S. (2012). Orienting and reorienting: the locus coeruleus mediates cognition through arousal. Neuron, 76(1), 130-141.

Schacter, D. L. (1999). The seven sins of memory. Insights from psychology and cognitive neuroscience. The American Psychologist, 54(3), 182-203. 
Schafe, G. E., \& LeDoux, J. E. (2000). Memory consolidation of auditory pavlovian fear conditioning requires protein synthesis and protein kinase A in the amygdala. Journal of Neuroscience, 20(18), RC96.

Schiller, D., Cain, C. K., Curley, N. G., Schwartz, J. S., Stern, S. A., LeDoux, J. E., \& Phelps, E. A. (2008). Evidence for recovery of fear following immediate extinction in rats and humans. Learning \& Memory, 15(6), 394-402.

Schroeder, J. P., \& Packard, M. G. (2003). Systemic or intra-amygdala injections of glucose facilitate memory consolidation for extinction of drug-induced conditioned reward. European Journal of Neuroscience, 17(7), 1482-1488.

Schroeder, J. P., \& Packard, M. G. (2004). Facilitation of memory for extinction of drug-induced conditioned reward: role of amygdala and acetylcholine. Learning \& Memory, 11(5), 641-647.

Schwabe, L., \& Wolf, O. T. (2009). Stress prompts habit behavior in humans. Journal of Neuroscience, 29(22), 7191-7198.

Schwabe, L., \& Wolf, O. T. (2012). Stress modulates the engagement of multiple memory systems in classification learning. Journal of Neuroscience, 32(32), 11042-11049.

Schwabe, L., \& Wolf, O. T. (2013). Stress and multiple memory systems: from 'thinking' to 'doing'. Trends in Cognitive Sciences, 17(2), 60-68.

Schwabe, L., Hoffken, O., Tegenthoff, M., \& Wolf, O. T. (2013a). Opposite effects of noradrenergic arousal on amygdala processing of fearful faces in men and women. NeuroImage, 73, 1-7.

Schwabe, L., Joëls, M., Roozendaal, B., Wolf, O. T., \& Oitzl, M. S. (2012). Stress effects on memory: An update and integration. Neuroscience \& Biobehavioral Reviews, 36(7), 1740-1749.

Schwabe, L., Oitzl, M. S., Philippsen, C., Richter, S., Bohringer, A., Wippich, W., \& Schachinger, H. (2007). Stress modulates the use of spatial versus stimulus-response learning strategies in humans. Learning \& Memory, 14(1), 109-116.

Schwabe, L., Tegenthoff, M., Hoffken, O., \& Wolf, O. T. (2013b). Mineralocorticoid receptor blockade prevents stress-induced modulation of multiple memory systems in the human brain. Biological Psychiatry, 74(11), 801-808.

Seeley, W. W., Menon, V., Schatzberg, A. F., Keller, J., Glover, G. H., Kenna, H., Reiss, A. L., et al. (2007). Dissociable intrinsic connectivity networks for salience processing and executive control. Journal of Neuroscience, 27(9), 2349-2356.

Seidenbecher, T., Laxmi, T. R., Stork, O., \& Pape, H.-C. (2003). Amygdalar and hippocampal theta rhythm synchronization during fear memory retrieval. Science, 301(5634), 846-850.

Senn, V., Wolff, S. B. E., Herry, C., Grenier, F., Ehrlich, I., Gründemann, J., Fadok, J. P., et al. (2014). Long-Range Connectivity Defines Behavioral Specificity of Amygdala Neurons. Neuron, 81(2), 428437. Elsevier Inc.

Siapas, A. G., Lubenov, E. V., \& Wilson, M. A. (2005). Prefrontal phase locking to hippocampal theta oscillations. Neuron, 46(1), 141-151.

Siebert, M., Markowitsch, H. J., \& Bartel, P. (2003). Amygdala, affect and cognition: evidence from 10 
patients with Urbach-Wiethe disease. Brain, 126(Pt 12), 2627-2637.

Singer, A. C., \& Frank, L. M. (2009). Rewarded outcomes enhance reactivation of experience in the hippocampus. Neuron, 64(6), 910-921.

Skaggs, W. E., \& McNaughton, B. L. (1996). Replay of neuronal firing sequences in rat hippocampus during sleep following spatial experience. Science, 271(5257), 1870-1873.

Smith, S. M., Fox, P. T., Miller, K. L., Glahn, D. C., Fox, P. M., Mackay, C. E., Filippini, N., et al. (2009). Correspondence of the brain's functional architecture during activation and rest. Proceedings of the National Academy of Sciences of the United States of America, 106(31), 13040-13045.

Staresina, B. P., Alink, A., Kriegeskorte, N., \& Henson, R. N. (2013). Awake reactivation predicts memory in humans. Proceedings of the National Academy of Sciences of the United States of America, 110(52), 21159-21164.

Sternberg, D. B., Isaacs, K. R., Gold, P. E., \& McGaugh, J. L. (1985). Epinephrine facilitation of appetitive learning: attenuation with adrenergic receptor antagonists. Behavioral and Neural Biology, 44(3), 447453.

Strange, B. A., \& Dolan, R. J. (2004). Beta-adrenergic modulation of emotional memory-evoked human amygdala and hippocampal responses. Proceedings of the National Academy of Sciences of the United States of America, 101(31), 11454-11458.

Takehara-Nishiuchi, K., \& McNaughton, B. L. (2008). Spontaneous changes of neocortical code for associative memory during consolidation. Science, 322(5903), 960-963.

Tambini, A., \& Davachi, L. (2013). Persistence of hippocampal multivoxel patterns into postencoding rest is related to memory. Proceedings of the National Academy of Sciences of the United States of America, 110(48), 19591-19596.

Tambini, A., Ketz, N., \& Davachi, L. (2010). Enhanced brain correlations during rest are related to memory for recent experiences. Neuron, 65(2), 280-290.

Terburg, D., Morgan, B. E., Montoya, E. R., Hooge, I. T., Thornton, H. B., Hariri, A. R., Panksepp, J., et al. (2012). Hypervigilance for fear after basolateral amygdala damage in humans. Translational psychiatry, 2, e115-e115.

Thornton, H. B., Nel, D., Thornton, D., van Honk, J., Baker, G. A., \& Stein, D. J. (2008). The neuropsychiatry and neuropsychology of lipoid proteinosis. The Journal of Neuropsychiatry and Clinical Neurosciences, 20(1), 86-92.

Tye, K. M., Prakash, R., Kim, S.-Y., Fenno, L. E., Grosenick, L., Zarabi, H., Thompson, K. R., et al. (2011). Amygdala circuitry mediating reversible and bidirectional control of anxiety. Nature, 471(7338), 358362.

Ulrich-Lai, Y. M., \& Herman, J. P. (2009). Neural regulation of endocrine and autonomic stress responses. Nature Reviews Neuroscience, 10(6), 397-409.

Valentino, R. J., \& van Bockstaele, E. (2008). Convergent regulation of locus coeruleus activity as an adaptive response to stress. European Journal of Pharmacology, 583(2-3), 194-203.

van den Heuvel, M. P., Mandl, R. C. W., Kahn, R. S., \& Hulshoff Pol, H. E. (2009). Functionally linked 
resting-state networks reflect the underlying structural connectivity architecture of the human brain. Human Brain Mapping, 30(10), 3127-3141.

van Kesteren, M. T. R., Fernández, G., Norris, D. G., \& Hermans, E. J. (2010). Persistent schema-dependent hippocampal-neocortical connectivity during memory encoding and postencoding rest in humans. Proceedings of the National Academy of Sciences of the United States of America, 107(16), 7550-7555.

van Kesteren, M. T. R., Ruiter, D. J., Fernández, G., \& Henson, R. N. (2012). How schema and novelty augment memory formation. Trends in Neurosciences, 35(4), 211-219.

van Marle, H. J. F., Hermans, E. J., Qin, S., \& Fernández, G. (2009). From specificity to sensitivity: how acute stress affects amygdala processing of biologically salient stimuli. Biological Psychiatry, 66(7), 649-655.

van Marle, H. J. F., Hermans, E. J., Qin, S., \& Fernández, G. (2010). Enhanced resting-state connectivity of amygdala in the immediate aftermath of acute psychological stress. NeuroImage, 53(1), 348-354.

van Marle, H. J. F., Hermans, E. J., Qin, S., Overeem, S., \& Fernández, G. (2013). The effect of exogenous cortisol during sleep on the behavioral and neural correlates of emotional memory consolidation in humans. Psychoneuroendocrinology, 38(9), 1639-1649.

van Stegeren, A. H., Goekoop, R., Everaerd, W., Scheltens, P., Barkhof, F., Kuijer, J. P. A., \& Rombouts, S. A. R. B. (2005). Noradrenaline mediates amygdala activation in men and women during encoding of emotional material. NeuroImage, 24(3), 898-909.

van Stegeren, A. H., Roozendaal, B., Kindt, M., Wolf, O. T., \& Joëls, M. (2010). Interacting noradrenergic and corticosteroid systems shift human brain activation patterns during encoding. Neurobiology of Learning and Memory, 93(1), 56-65.

van Stegeren, A. H., Wolf, O. T., Everaerd, W., Scheltens, P., Barkhof, F., \& Rombouts, S. A. R. B. (2007). Endogenous cortisol level interacts with noradrenergic activation in the human amygdala. Neurobiology of Learning and Memory, 87(1), 57-66.

Vazdarjanova, A., \& McGaugh, J. L. (1999). Basolateral amygdala is involved in modulating consolidation of memory for classical fear conditioning. Journal of Neuroscience, 19(15), 6615-6622.

Vouimba, R.-M., \& Richter-Levin, G. (2005). Physiological dissociation in hippocampal subregions in response to amygdala stimulation. Cerebral Cortex, 15(11), 1815-1821.

Vouimba, R.-M., \& Richter-Levin, G. (2013). Different patterns of amygdala priming differentially affect dentate gyrus plasticity and corticosterone, but not CA1 plasticity. Frontiers in Neural Circuits, 7, 80.

Vouimba, R.-M., Yaniv, D., \& Richter-Levin, G. (2007). Glucocorticoid receptors and beta-adrenoceptors in basolateral amygdala modulate synaptic plasticity in hippocampal dentate gyrus, but not in area CA1. Neuropharmacology, 52(1), 244-252.

Vuilleumier, P., Richardson, M. P., Armony, J. L., Driver, J., \& Dolan, R. J. (2004). Distant influences of amygdala lesion on visual cortical activation during emotional face processing. Nature Neuroscience, $7(11), 1271-1278$.

Weiskrantz, L. (1956). Behavioral changes associated with ablation of the amygdaloid complex in monkeys. Journal of Comparative and Physiological Psychology, 49(4), 381-391. 
Whalen, P. (2007). The uncertainty of it all. Trends in Cognitive Sciences, 11(12), 499-500.

Wierzynski, C. M., Lubenov, E. V., Gu, M., \& Siapas, A. G. (2009). State-dependent spike-timing relationships between hippocampal and prefrontal circuits during sleep. Neuron, 61(4), 587-596.

Wilensky, A. E., Schafe, G. E., \& LeDoux, J. E. (2000). The amygdala modulates memory consolidation of fear-motivated inhibitory avoidance learning but not classical fear conditioning. Journal of Neuroscience, 20(18), 7059-7066.

Wilhelm, I., Wagner, U., \& Born, J. (2011). Opposite effects of cortisol on consolidation of temporal sequence memory during waking and sleep. Journal of Cognitive Neuroscience, 23(12), 3703-3712.

Williams, C. L., Men, D., Clayton, E. C., \& Gold, P. E. (1998). Norepinephrine release in the amygdala after systemic injection of epinephrine or escapable footshock: contribution of the nucleus of the solitary tract. Behavioral Neuroscience, 112(6), 1414-1422.

Wilson, M. A., \& McNaughton, B. L. (1994). Reactivation of hippocampal ensemble memories during sleep. Science, 265(5172), 676-679.

Zanatta, M. S., Schaeffer, E., Schmitz, P. K., Medina, J. H., Quevedo, J., Quillfeldt, J. A., \& Izquierdo, I. (1996). Sequential involvement of NMDA receptor-dependent processes in hippocampus, amygdala, entorhinal cortex and parietal cortex in memory processing. Behavioural Pharmacology, 7(4), 341-345.

Zorawski, M., \& Killcross, S. (2002). Posttraining glucocorticoid receptor agonist enhances memory in appetitive and aversive Pavlovian discrete-cue conditioning paradigms. Neurobiology of Learning and Memory, 78(2), 458-464. 

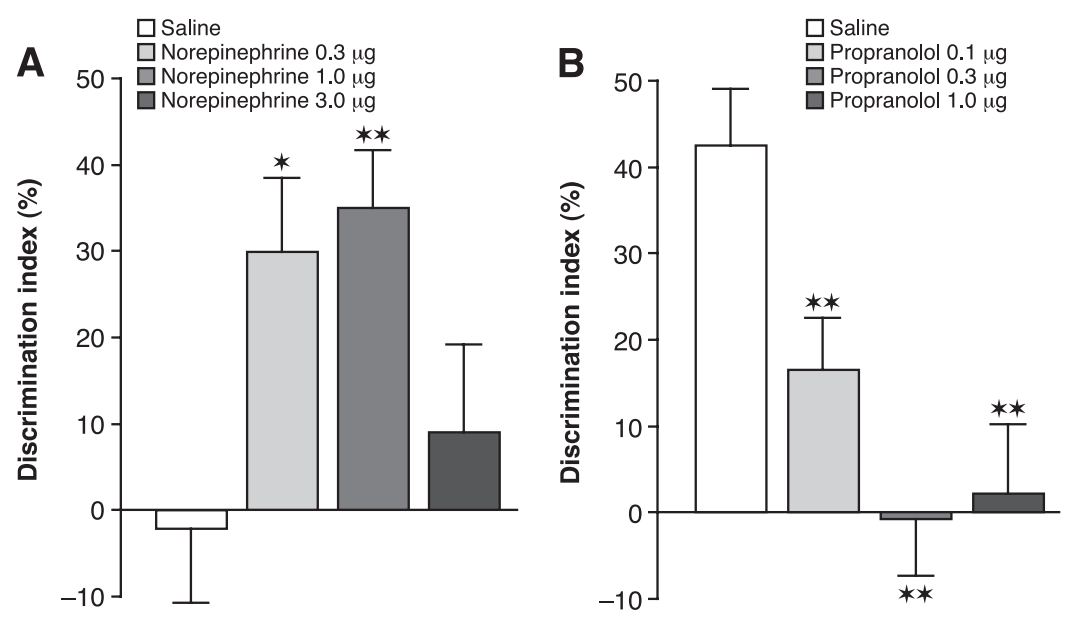

Figure 1. Noradrenergic activation of the basolateral amygdala modulates consolidation of object recognition memory. (A) Enhancing effects of posttraining intrabasolateral amygdala infusions of norepinephrine on 24-hr object recognition memory. Saline-infused controls displayed no evidence of memory of $3 \mathrm{~min}$ of training. The retention performance of groups given norepinephrine ( 0.3 or $1.0 \mu \mathrm{g}$ in 0.2 $\mu 1)$ after training was significantly better than that of saline controls. Data presented as discrimination index (mean $\pm \mathrm{SEM}$ ) in percentage on the 24-hr retention trial. The discrimination index was calculated as the difference in time spent exploring the two objects, expressed as the ratio of the total time spent exploring both objects. (B) Impairing effects of posttraining intrabasolateral amygdala infusions of the $\beta$-adrenoceptor antagonist propranolol on 24-hr object recognition memory. All groups received 10 minutes of training. Saline-infused controls displayed significant memory and propranolol $(0.1,0.3$ or $1.0 \mu \mathrm{g}$ in $0.2 \mu \mathrm{l})$ produced dose-dependent impairment of memory. The performance of all three propranolol groups differed significantly from that of the corresponding saline controls. ${ }^{*}, \mathrm{p}<.05 ; * *, \mathrm{p}<.01$ compared with the corresponding saline controls. From "Noradrenergic Activation of the Basolateral Amygdala Modulates Consolidation of Object Recognition Memory,” by B. Roozendaal, N. Castello, G. Vedana, A. Barsegyan, and J. L. McGaugh, 2008, Neurobiology of Learning and Memory, 90, p. 578. Copyright 2008 by Elsevier. 


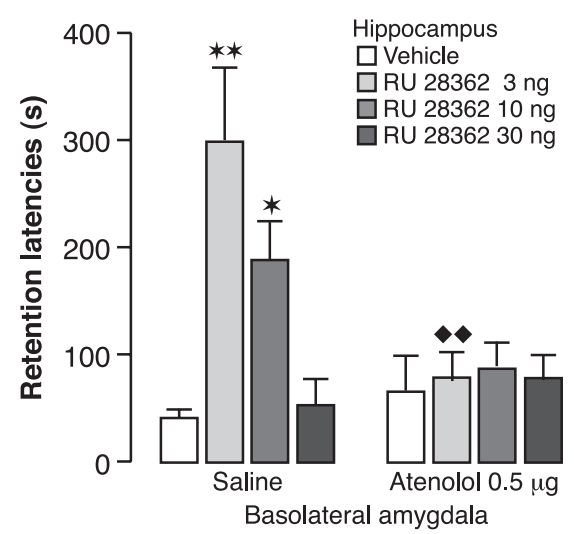

Figure 2. Glucocorticoid effects in the hippocampus on memory consolidation require noradrenergic activity of the basolateral amygdala. Immediate posttraining unilateral infusions of the glucocorticoid receptor agonist RU $28362(3,10$, or $30 \mathrm{ng}$ in $0.5 \mu \mathrm{l})$ into the hippocampus induced dose-dependent enhancement of 48-hr inhibitory avoidance retention latencies in rats given saline infusions into the basolateral amygdala concurrently. Ipsilateral infusions of the $\beta$-adrenoceptor antagonist atenolol $(0.5 \mu \mathrm{g}$ in $0.2 \mu \mathrm{l})$ into the basolateral amygdala blocked the memory enhancement induced by the glucocorticoid receptor agonist. Results represent retention latencies (mean \pm SEM) in seconds. ${ }^{*}, \mathrm{p}<.05 ; * *, \mathrm{p}<.01$ compared with the corresponding vehicle group. ${ }^{* *}, \mathrm{p}<.01$ compared with the corresponding saline group. From "Basolateral Amygdala Noradrenergic Influence Enables Enhancement of Memory Consolidation Induced by Hippocampal Glucocorticoid Receptor Activation," by B. Roozendaal, B. T. Nguyen, A. Power, and J. L. McGaugh, 1999, Proceedings of the National Academy of Sciences of the USA, 96, p. 11645. Copyright 1999 by the National Academy of Sciences. 

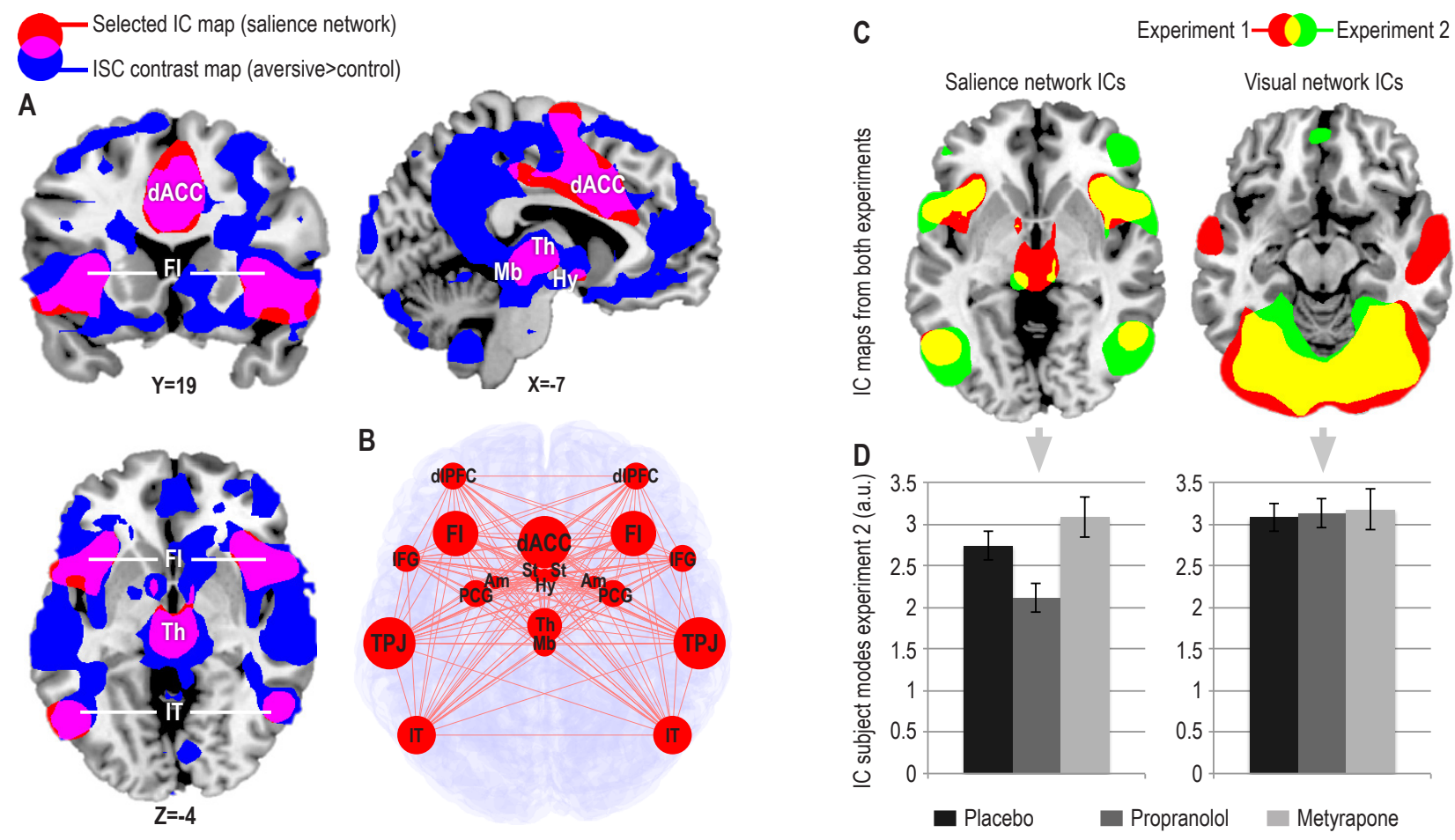

Figure 3. (A) Regions comprising the salience network overlaid onto a canonical T1-weighted MRI scan. (B) Schematic overview of suprathreshold clusters and relative sizes within the salience network. In experiment 1, salience network connectivity correlated with multiple measures of stress. (C) Overlap between the salience work and visual (control) networks in correlational (1) and pharmacological (2) experiments. (D) Drug effects on functional connectivity strength (+- SEM) within salience and visual networks in experiment 2. Beta-adrenoceptor blockade lowered functional connectivity within the salience network but not within the control network. FI, frontoinsular cortex; dACC, dorsal anterior cingulate cortex; $\mathrm{Mb}$, midbrain; Hy, hypothalamus; Th, thalamus; IT, inferotemporal cortex; TPJ, temporoparietal junction; Am, amygdala; IFG, inferior frontal gyrus; PCG, precentral gyrus; dlPFC, dorsolateral prefrontal cortex; St, striatum (caudate/pallidum). From "Stress-related noradrenergic activity prompts large-scale neural network reconfiguration.," by E.J. Hermans et al., 2011, Science, 334, p. 1151. Reprinted with permission from AAAS. 